Georgia State University

ScholarWorks @ Georgia State University

Counseling and Psychological Services

Dissertations

Department of Counseling and Psychological

Services

8-7-2012

\title{
Professional Counselors' Conceptualizations of the Relationship between Suicide and Self-Injury
}

Julia L. Whisenhunt

Georgia State University

Follow this and additional works at: https://scholarworks.gsu.edu/cps_diss

\section{Recommended Citation}

Whisenhunt, Julia L., "Professional Counselors' Conceptualizations of the Relationship between Suicide and Self-Injury." Dissertation, Georgia State University, 2012.

doi: https://doi.org/10.57709/3038648

This Dissertation is brought to you for free and open access by the Department of Counseling and Psychological Services at ScholarWorks @ Georgia State University. It has been accepted for inclusion in Counseling and Psychological Services Dissertations by an authorized administrator of ScholarWorks @ Georgia State University. For more information, please contact scholarworks@gsu.edu. 


\section{ACCEPTANCE}

This dissertation, PROFESSIONAL COUNSELORS' CONCEPTUALIZATIONS OF THE RELATIONSHIP BETWEEN SUICIDE AND SELF-INJURY, by JULIA LIZABETH WHISENHUNT, was prepared under the direction of the candidate's Dissertation Advisory Committee. It is accepted by the committee members in partial fulfillment of the requirements for the degree Doctor of Philosophy in the College of Education, Georgia State University.

The Dissertation Advisory Committee and the student's Department Chair, as representatives of the faculty, certify that this dissertation has met all standards of excellence and scholarship as determined by the faculty. The Dean of the College of Education concurs.

Catherine (Catharina) Y. Chang, Ph.D.

Committee Chair

Jonathan Orr, Ph.D.

Committee Member
Greg Brack, Ph.D.

Committee Member

Date

Brian Dew, Ph.D.

Chair, Department of Counseling and Psychological Services

R. W. Kamphaus, Ph.D.

Dean and Distinguished Research Professor

College of Education

Lisa Adams, Ph.D.

Committee Member 


\begin{abstract}
AUTHOR'S STATEMENT
By presenting this dissertation as a partial fulfillment of the requirements for the advanced degree from Georgia State University, I agree that the library of Georgia State University shall make it available for inspection and circulation in accordance with its regulations governing materials of this type. I agree that permission to quote, to copy from, or to publish this dissertation may be granted by the professor under whose direction it was written, by the College of Education's director of graduate studies and research, or by me. Such quoting, copying, or publishing must be solely for scholarly purposes and will not involve potential financial gain. It is understood that any copying from or publication of this dissertation which involves potential financial gain will not be allowed without my written permission.
\end{abstract}

Julia L. Whisenhunt 


\section{NOTICE TO BORROWERS}

All dissertations deposited in the Georgia State University library must be used in accordance with the stipulations prescribed by the author in the preceding statement. The author of this dissertation is:

\section{Julia L. Whisenhunt \\ 514 Plowshare Rd. \\ Carrollton, GA 30117}

The director of this dissertation is:

Dr. Catherine Y. Chang (Catharina)

Department of Counseling and Psychological Services

College of Education

Georgia State University

Atlanta, GA 30302-3980 
VITA

\section{Julia Whisenhunt}

ADDRESS: $\quad 514$ Plowshare Rd.

Carrollton, GA 30117

EDUCATION: $\quad$ Ph.D. 2012 Georgia State University

Counselor Education and Practice

Ed.S. 2009 University of West Georgia

Guidance and Counseling

M.A. 2003 State University of West Georgia

Psychology

B.A. 2001 State University of West Georgia

Psychology

PROFESSIONAL EXPERIENCE:

2011-2012 Counseling Intern

University of West Georgia, Carrollton, GA

2009-2011 Counseling Intern

GIVE Center West, Norcross, GA

2009 Counseling Intern

University of West Georgia, Carrollton, GA

2006-Present Volunteer

Willowbrooke at Tanner, Carrollton, GA

$2006 \quad$ Counseling Intern

Tanner Behavioral Health, Carrollton, GA

2010-2012 Graduate Teaching Assistant

Georgia State University, Atlanta, GA

$2006 \quad$ Adjunct Instructor

West Central Technical College, Douglasville, GA

2004-2012 Instructor

University of West Georgia, Carrollton, GA

PROFESSIONAL SOCIETIES AND ORGANIZATIONS:

2012-Present International Society for the Study of Self-Injury

2012-Present American College Counseling Association

2012-Present Association for Assessment in Counseling and

Education

2011-Present Association for Counselor Education and Supervision

2010-Present Association for Creativity in Counseling

2010-Present Southern Association for Counselor Education and Supervision

2009-Present American Counseling Association

2008-Present Georgia College Counseling Association 
PRESENTATIONS AND PUBLICATIONS:

Whisenhunt, J., \& Kress, V. (2012). The Use of Visual Arts in Counseling Clients who Engage in Non-Suicidal Self-Injury. Manuscript under review.

Whisenhunt, J., Chang, C., Flowers, L., Brack, G., O’Hara, C., \& Raines, T. (2012). Working with clients who self-injure: A grounded theory approach. Manuscript under review

Whisenhunt, J., \& O'Hara, C. (2012, March). Working with clients who self-injure: A grounded theory approach. American Counseling Association. San Francisco, CA.

Fletcher, D., \& Whisenhunt, J. (March 2012). PREVENT @ UWG. Suicide Prevention at Colleges. Universities in Georgia, Athens, GA.

Whisenhunt, J., \& Edwards, S. (2011, October). MBTI: Personality Inventory and Clinical Tool. Association for Counselor Education and Supervision. Nashville, TN.

Whisenhunt, J. (2011, August). Department of Nursing Annual Faculty and Staff Retreat, Group Building Workshop. University of West Georgia. Carrollton, GA.

Flowers, L., Whisenhunt, J., Shelton, L., Grubbs, N., \& Lokkesmoe, K. (2011, March). Introduction to post-traumatic growth: The transformative side of trauma. American Counseling Association Conference. New Orleans, LA.

Whisenhunt, J. (2011, February). Play therapy. University of West Georgia Guest Lecture. Carrollton, GA.

Whisenhunt, J. (2011, January). Expressive interventions for use with the adult population. Georgia College Counseling Association Conference. St. Simon's Island, GA.

Whisenhunt, J. (2011, January). Counselors' approach to working with clients who selfinjure. Georgia State University Department of Counseling and Psychological Services Research Expo. Atlanta, GA.

Flowers, L., Whisenhunt, J., Shelton, L., Lokkesmoe, K., \& Kargar, N. (2010, October). Post-traumatic growth and counselors in training. Southern Association for Counselor Education and Supervision Conference. Williamsburg, VA.

Whisenhunt, J. (2010, January). Sandtray therapy in college counseling: Preparations and considerations. Georgia College Counseling Association Conference. St. Simon's Island, GA. 


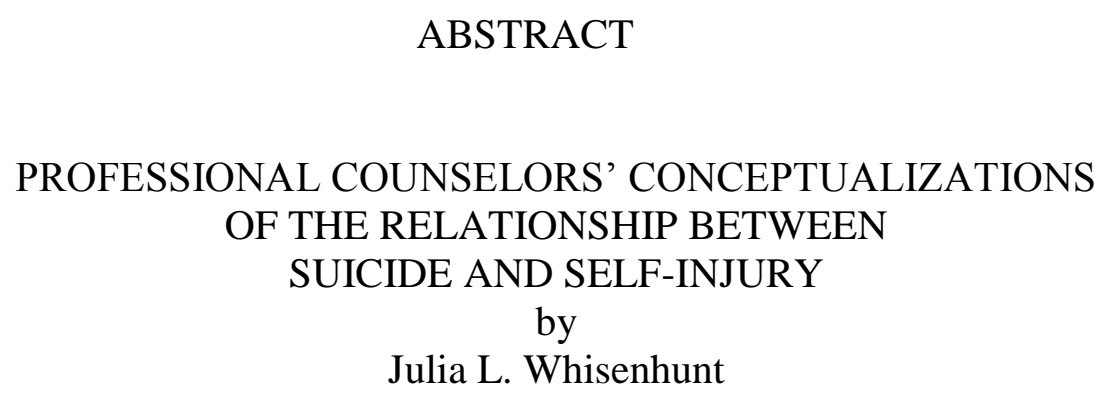

Research that explores the relationship between suicide and self-injury is limited, and the lack of clarity surrounding this topic can present challenges for professional counselors. Although persons who self-injure are at an increased risk for suicide (e.g., Toprak, Cetin, Guven, Can, \& Demircan, 2011; Chapman \& Dixon-Gordon, 2007), not all individuals who engage in self-injurious behaviors attempt or complete suicide (e.g., Hawton \& Harriss, 2008; Howson, Yates, \& Hatcher, 2008). Research on common and distinct risk factors for suicide and self-injury (e.g., Andover, Primack, Gibb, \& Pepper, 2010; Brausch \& Gutierrez, 2010; Greydanus \& Apple, 2011; Hawton \& James, 2005; LloydRichardson, Perrine, Dierker, \& Kelley, 2007; Toprak et al., 2011; Wichstrom, 2009), as well as emotional antecedents and consequences for suicide and self-injury (e.g., Chapman \& Dixon-Gordon, 2007), has contributed to our understanding of this complex relationship. However, the specific nature of the relationship remains unclear. This study serves to help fill the gap in the literature by examining advanced professional counselors', as measured by the Supervisee Levels Questionnaire-Revised, conceptualizations of the relationship between suicide and self-injury and by exploring how the presence of self-injury impacts clinical assessment and interventions. Data was collected by means of an online survey. Analysis was conducted by a research team using qualitative content analysis. Seven categories emerged, including: relationship between 
suicide and self-injury, functions of self-injury, associated risk, suicide risk assessment, treatment planning and goals, intervention, and identification of self-injury. 


\title{
PROFESSIONAL COUNSELORS' CONCEPTUALIZATIONS OF THE RELATIONSHIP BETWEEN \\ SUICIDE AND SELF-INJURY \\ by \\ JULIA L. WHISENHUNT
}

\author{
A Dissertation \\ Presented in Partial Fulfillment of Requirements for the \\ Degree of \\ Doctor of Philosophy \\ in \\ Counselor Education and Practice \\ in \\ the Department of Counseling and Psychological Services \\ in \\ the College of Education \\ Georgia State University
}

Atlanta, GA

2012 
Copyright by

Julia L. Whisenhunt 2012 


\section{ACKNOWLEDGEMENTS}

To my dissertation chair and advisor, Dr. Catharina Chang, thank you for your mentorship, patience, and support throughout this process.

To my dissertation committee, Drs. Greg Brack, Jonathan Orr, and Lisa Adams, thank you all for your encouragement, guidance, and support.

To the research team, Ms. Melinda Paige and Mrs. Peeper McDonald, this has been a collaborative effort and I believe you both share equally in this success.

To Ms. Caroline O'Hara, you are an outstanding colleague and a remarkable editor. Thank you.

To my spouse, Duane, who has unwaveringly supported me throughout each of my academic pursuits, I would not be here without you.

To my family, Julie, Nathan, Giovanna, and Wayne, thank you for always believing in me. 


\section{TABLE OF CONTENTS}

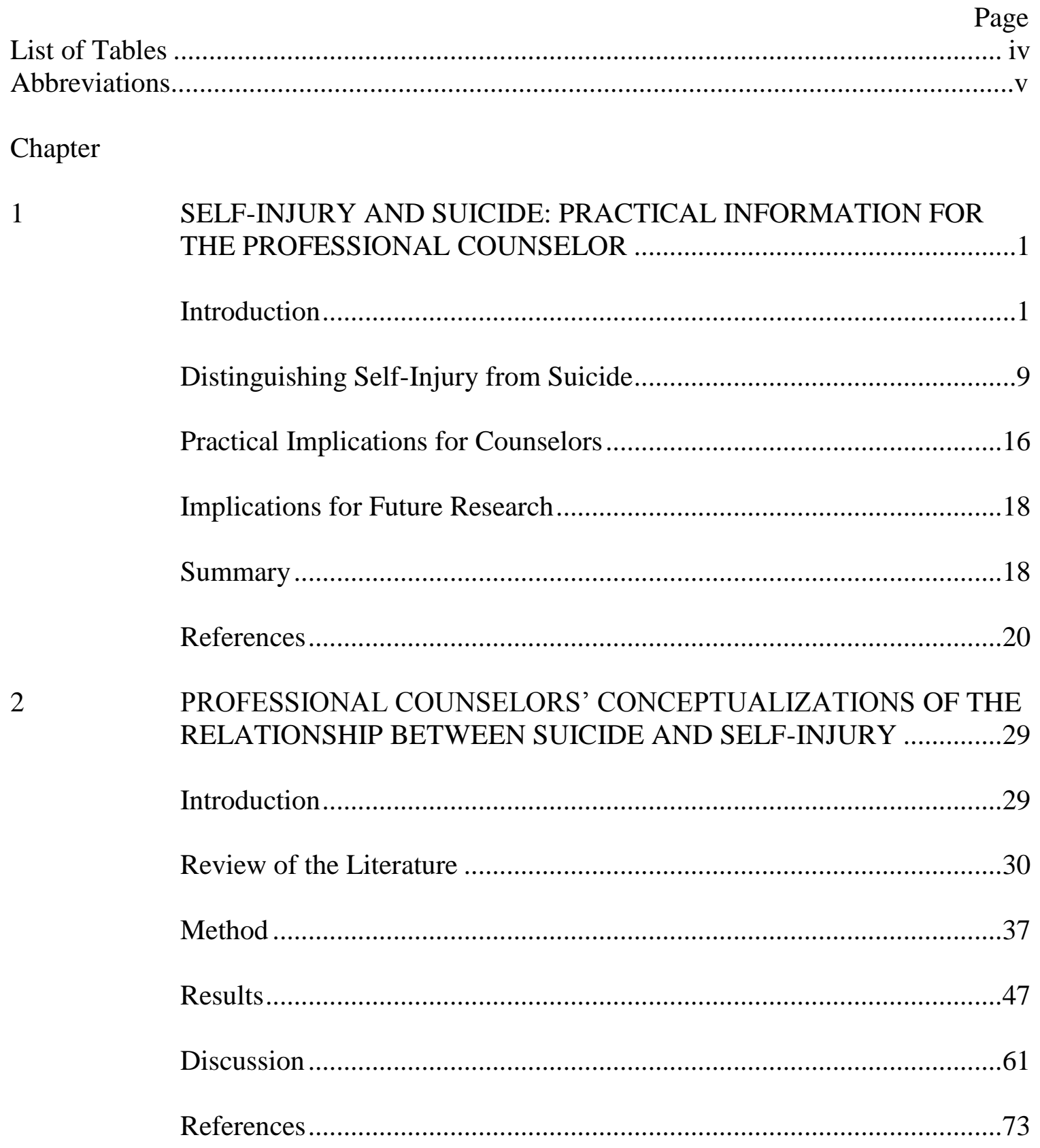




\section{LIST OF TABLES}

Table

Page

1

Demographic Distribution of the Sample

2

Scale Statistics for SLQ-R Responses

Cronbach's Alpha for SLQ-R Responses ....

Categories, Subcategories, Frequency Counts, Definitions .....................48

Response Exclusiveness and Inclusiveness .51 


\section{ABBREVIATIONS}

AAS

ANOVA

CDC

CITs

IDM

NSDUH

SAMHSA

SLQ-R

USDHHS
American Association of Suicidology

Analysis of Variance

Centers for Disease Control

Counselors in Training

Integrated Developmental Model

National Survey on Drug Use and Health

Substance Abuse and Mental Health Services Administration

Supervisee Levels Questionnaire-Revised

U.S. Department of Health and Human Services 


\section{CHAPTER 1}

\section{SELF-INJURY AND SUICIDE:}

\section{PRACTICAL INFORMATION FOR THE PROFESSIONAL COUNSELOR}

Self-injury and suicide are relatively common, dangerous, challenging to predict, and difficult to treat (Janis \& Nock, 2008), making them potentially the most anxietyprovoking therapeutic treatment issues. Indeed, losing a client to suicide is likely every professional counselor's worst fear. Similarly, self-injury evokes strong reactions from professional and lay communities alike (White, McCormick, \& Kelly, 2003). Though not fully understood, there exists a relationship between these two phenomena-one in which those who self-injure are at an increased risk of suicide (Chapman \& Dixon-Gordon, 2007). A complete picture of the relationship between self-injury and suicide is not yet fully understood. Nonetheless, professional counselors should be familiar with various self-injurious and parasuicidal behaviors, signs of heightened risk, and specific indications for treatment. In this paper, the author presents an overview of suicide and self-injury, followed by practical implications for the professional counselor.

\section{Brief Overview of Suicide}

According to the U.S. Department of Health and Human Services (USDHHS), suicide is defined as deliberate and fatal self-harm with the presence of some intent to die as a result of the behavior (USDHHS, 2009a). It is a major worldwide public health issue (Bebbington et al., 2010) and, as such, a great deal of effort has been directed towards achieving a better understanding of suicide. When discussing suicide, it is important to differentiate between risk factors, warning signs, crisis, attempts, and completions. Risk factors for suicide are those factors that have been empirically linked to suicide, such as 
gender, age, previous suicidal attempts, psychiatric diagnosis (Rudd et al., 2006) and childhood physical abuse (Fuller-Thomson, Baker, \& Brennenstuhl, 2012). Rudd et al. (2006) proposed a differentiation of warning signs for suicide from risk factors, wherein warning signs indicate a near-term threat and risk factors indicate a long-term threat. Examples of warning signs include isolation, drastic changes in mood, hopelessness, anger and acting out, and increased use of alcohol and/or drugs. Stated concisely, warning signs for suicide are behavioral and observable (Van Orden et al., 2006), episodic and variable, and require immediate intervention (Rudd et al., 2006). Those specific events that require immediate intervention due to an imminent threat of a suicide attempt or completion are otherwise referred to as suicide crises (Rudd et al., 2006).

Prevalence of suicide. Although an accurate index of suicide statistics is difficult to calculate precisely due to deaths under unknown or questionable circumstances, rates of known suicide are relatively consistent across studies. According to a National Viral Statistics Report issued by the USDHHS, there were a total of 35,933 completed suicides in 2008, making suicide the eleventh leading cause of death in the United States during that year (USDHHS, 2010a). An analysis by the American Association of Suicidology (AAS) yielded similar results for 2008, reporting a total of 36,035 completed suicides, making suicide the tenth leading cause of death (McIntosh, 2008). One person completes suicide approximately every 14.6 minutes, and for each of those completed suicides, an average of at least six people are intimately affected (McIntosh, 2008).

Suicide attempts occur with much greater frequency than completed suicides. A USDHHS (2010b) report from the National Survey on Drug Use and Health examined suicidal thoughts and behaviors among adults during the years 2008 and 2009, indicating 
that an estimated 1.1 million U.S. adults, or 0.5 percent of the population, attempted suicide during the respective time frame. These figures equate to approximately 25 suicide attempts for every completed suicide which translates to one suicide attempt every 35 seconds (McIntosh, 2008). The National Center for Injury Prevention and Control reported disparate figures for 2009, estimating 374,486 non-fatal self-harm injuries (USDHHS, 2011). Differences in data collection procedures, such as, analyzing emergency room visits versus surveys of self-reports, may account for some of the differences in rates of suicide attempts. In fact, only approximately $61 \%$ of persons who attempt suicide seek medical attention for the attempt (USDHHS, 2010b). Accordingly, as with completed suicide, the actual rates of suicide attempts cannot be known.

Suicidal thoughts, such as considering taking one's own life or imagining that death would be better than continuing to live (e.g., USDHHS, 2006), occur frequently and warrant attention. According to the USDHHS (2010b), an estimated 8.4 million U.S. adults, age 18 years and older, seriously contemplated suicide within the 2008 to 2009 time frame. Of those 8.4 million people, 2.3 million had a suicide plan (USDHHS, 2010b). These figures translate to $3.7 \%$ U.S. adults who seriously considered suicide and $1.0 \%$ of the U.S. adult population who created a suicide plan during the respective time frame (USDHHS, 2009b, 2010b).

Rates of suicide vary by age and gender, with the most current data indicating the highest rates among the 18 to 25-year-old age group and those who are unemployed (USDHHS, 2010b). Adolescents and young adults have not always accounted for the age group of highest suicide risk. According to the 2007 National Vital Statistics Reports, the suicide rate for older adults (i.e., ages 80 and older) was approximately 50 percent higher 
than all other age groups (AAS, 2007). It is unclear whether this discrepancy is the result of a shift in suicide trends or the reflection of differences in data collection procedures. Gender differences are also noteworthy. Although females accounted for approximately three times as many suicide attempts as males, males accounted for approximately 3.6 (AAS, 2007) to 3.75 (McIntosh, 2008) times as many completed suicides as females. Worldwide, the most common method of suicide for men is hanging, and the most common method for women is self-poisoning (Windfuhr \& Kapur, 2011).

\section{Brief Overview of Self-Injury}

Self-injury is a purposeful act of self-harm, not done for body modification or adornment. It involves tissue damage in the absence of the conscious intention to die as a result of the self-harm act (Nock, 2009; Weierich \& Nock, 2008; Whisenhunt \& Kress, 2012). Although it is often considered maladaptive among the lay community, many mental health professionals conceptualize self-injury as a coping skill through which some people have learned to deal with difficult emotions (Haines \& Williams, 2003). Self-injury is viewed as the result of real, intense pain among people who have no other means to cope with that pain (Moyer, 2008) or for whom other coping strategies have not worked effectively (Klonsky, Muehlenkamp, Lewis, \&Walsh, 2011). In this sense, selfinjury can be considered life-sustaining for some people (Alderman, 1997). According to Wester and Trepal (2005), "it appears that self-injury assists individuals in keeping or gaining control over their lives, whether it is in the form of controlling emotions or pain, feeling 'real,' or expressing oneself' (p. 182).

Multiple functions of self-injury have been explored in the literature. Current research supports five functions of self-injury: emotion regulation, feeling generation, 
self-punishment, interpersonal influence, and interpersonal communication. Self-injury may serve multiple functions for a given individual (Turner, Chapman, \& Layden, 2012). Emotion regulation is the most frequently reported reason for self-injuring and refers to the use of self-injury to abate particularly aversive feelings, such as guilt and rage (Klonsky \& Muehlenkamp, 2007; Turner et al., 2012). Feeling generation refers to using self-injury as a means of coping with numbness or depersonalization (Turner et al., 2012). Feeling generation is also sometimes referred to as antidissociation because selfinjury can have the effect of helping the person feel real again (Klonsky \& Muehlenkamp, 2007). Self-punishment is a common function of self-injury and involves personal attacks on the self as a means of expressing anger towards one's self (Klonsky \& Muehlenkamp, 2007) or as a means of stopping feelings of self-hatred (Turner et al., 2012). Interpersonal influence involves the use of self-injury either to get others to act differently or to seek revenge (Turner et al., 2012). This function of self-injury is controlling in nature, whereas the interpersonal communication function reflects the selfinjurer's efforts to communicate her or his distress to others.

There are various types of self-injury reported in the literature, including cutting, hitting, pin-pricking, skin-picking, burning, swallowing foreign objects, and headbanging (Trepal \& Wester, 2007). Although cutting is typically the type of self-injury most commonly reported (Poland, 2008; Polk \& Liss, 2009; Trepal \& Wester, 2007), severely scratching and pinching the skin are also frequently found (Whitlock, Eckenrode, \& Silverman, 2006). People who self-injure may also engage in dangerous acts, such as instigating physical altercations, as a means of intentionally having harm inflicted upon them (Whitlock et al., 2006). Although self-injury can be inflicted on any 
place on the body, the arms, hands, wrists, thighs stomach, calves, head, and fingers are among the most common injury sites (Whitlock et al., 2006).

Prevalence of self-injury. An accurate estimation of rates of self-injury is complicated, in part, because there has not yet been a nationwide epidemiological study of self-injury (Walsh, 2006). Although the figures presented on lifetime prevalence rates of self-injury differ by study (Laye-Gindhu \& Schonert-Reichl, 2005), adults typically represent the lowest rates (Jacobson \& Gould, 2007). Jacobson and Gould (2007) found a lifetime prevalence rate of 13 to $23 \%$ for adolescents, whereas Craigen, Healey, Walley, Byrd, and Schuster (2010) found estimates of adolescent self-injury ranging from 4 to $39 \%$. Rates among adults remain noteworthy, with approximately $4 \%$ of U.S. adults acknowledging having self-injured at some point in their lives (Briere \& Gil, 1998; Klonsky, Oltmanns, \& Turkheimer, 2003). These rates tend to continue decreasing with age (Hawton \& Harriss, 2008); however, Nock (2009) pointed to the possibility that decreased rates among adults could also be the result of denial regarding self-injurious behavior. Although the onset of self-injury tends to occur during adolescence (Jacobson \& Gould, 2007), self-injury is not restricted by age.

Self-injury does not discriminate among genders, race, or ethnicity. Although it has long been believed that self-injury occurred almost exclusively among females (Laye-Gindhu \& Schonert-Reichl, 2005), recent studies have reported similar prevalence rates for males and females (e.g., Andover et al., 2010; Lloyd-Richardson, Perrine, Dierker, \& Kelley, 2007). This gender gap may be attributed to sampling patterns that do not include males (Kakhnovets, Young, Purnell, Huebner, \& Bishop, 2010; Laye-Gindhu \& Schonert-Reichl, 2005) and gender differences in types of self-injury (Klonsky \& 
Muehlenkamp, 2007). Similarly, whereas there appears to be a greater prevalence of selfinjury among the White population (Gratz, 2006), some evidence supports higher rates among the Native American and Latino/a adolescent populations than among their White and Black/African American counterparts (Evans, Evans, Morgan, Hayward, \& Gunnell, 2005). Further research is necessary to ascertain whether there exists an underrepresentation of racial and ethnic minority groups in studies of self-injury.

Prevalence of comorbid self-injury and suicide. People who self-injure are at increased risk of suicide (Toprak et al., 2011); however, rates of self-injury far surpass those of completed suicide. Not all persons who self-injure will attempt or complete suicide. Unfortunately, there is a lack of consistency regarding the exact ratio of selfinjury to suicide (Hawton \& Harriss, 2008). In addition, the classification of non-suicidal self-injury in the same category as suicidal attempts complicates the interpretation of data (Klonsky et al., 2011). Nonetheless, studies that categorize self-injury under the umbrella of suicide help to illustrate the frequency with which suicide occurs in relation to other parasuicidal behaviors.

In their review of records from a ten year period of hospital admissions to one U.K. medical facility, Hawton and Harriss (2008) found a ratio of approximately 26.2:1, wherein an estimated 26.2 people engage in some form of self-injury, including potential suicide attempts, to every completed suicide. In a study based in Australia, Howson et al., (2008) found a suicide rate of $1.1 \%$ among persons who present to the hospital with selfinflicted injuries — whether suicidal or non-suicidal in intent.

Some studies have differentiated and examined the frequency of self-injury to suicidal ideation and attempts. Across these studies, no single pattern of frequency among 
suicidal ideation, self-injury, and suicidal attempts can be established. Gunter, Philibert, and Hollenbeck (2009) examined medical and mental health morbidity rates among nonincarcerated persons who had committed criminal acts and were served by residential facilities. In their sample of 330 volunteers, 38\% acknowledged suicidal ideation, 17\% reported suicide attempts, and $12 \%$ stated they engaged in volitional self-injury (Gunter et. al., 2009). Toprak et al., (2011) found a different relationship in the frequency of suicidal ideation, self-injury, and suicidal attempts in their study of over 600 undergraduate Turkish students. Their results yielded a lifetime prevalence rate of $11.4 \%$ for suicidal ideation, $7.1 \%$ for suicide attempts, and $15.4 \%$ for self-injury (Toprak et al., 2011). In their survey of over 500 undergraduate and graduate students, Kakhnovets et al., (2010) found that $15.7 \%$ of participants reported at least one episode of non-suicidal self-injury and that $8.5 \%$ of participants experienced suicidal ideation in the absence of a history of self-injury. Of those study participants who reported more than one episode of self-injury, nearly $60 \%$ also reported suicidal ideation. This figure is approximately twice that of persons who reported a single self-injurious episode (31.8\%; Kakhnovets et al., 2010). These differing relationships in frequency rates between self-injury and suicidal ideation and attempts may be accounted for by the dissimilar sample populations. Further research in this area is needed.

\section{Distinguishing Self-Injury from Suicide}

Self-injury and suicide share some similarities, but they also differ in important ways (Chapman \& Dixon-Gordon, 2007; Muehlenkamp \& Gutierrezz, 2004; Wester \& Trepal, 2005). However, a lack of consensus regarding the conceptualization and definition of self-injury (Chapman \& Dixon-Gordon, 2007; Nock \& Favazza, 2009) has 
complicated the process of explicating those differences. Some authors argue that selfinjury exists along a continuum of suicidal intent and cannot be clearly distinguished from suicidal attempts (e.g., Hawton \& Harris, 2008; Hawton, Harris, \& Rodman, 2010; Hawton \& James, 2005; Howson, Yates, \& Hatcher, 2008). Other authors distinguish self-injury and suicide by pointing to the multiple non-suicidal functions of self-injury, such as emotion regulation, emotion expression, and distraction (Chapman \& DixonGordon, 2007) and by noting differences in intent, frequency, severity, and methods (Klonsky et al., 2011; Walsh, 2006). Those who distinguish self-injury from suicide may still conceptualize self-injury as a point along a continuum, which falls below suicidal attempts (e.g., Muehlenkamp \& Gutierrezz, 2007). Regardless, some significant distinctions exist between self-injury and suicide. Given the prevalence rates for both self-injury and suicide, the strong reactions these terms evoke in professional counselors (White et al., 2003), and the lack of training and resources for working with clients who self-injure (Hoffman \& Kress, 2010), it is essential that professional counselors have an understanding of the commonalities and the differences between self-injury and suicide.

One means of exploring the distinguishing characteristics of self-injury and suicide is to look at the emotional antecedents and consequences to each action. Chapman and Dixon-Gordon (2007) found that anger was an emotional antecedent for self-injury, suicidal attempts, and ambivalent suicidal attempts in a group of 117 female inmates; however those who self-injured reported a marked decrease in anger following the behavior, whereas those who attempted suicide did not report a decrease in anger. This study did not distinguish between different types of anger and their relationship to selfinjury and suicide. They also found that boredom was more often an emotional 
antecedent for self-injury than for suicidal attempts or ambivalent suicidal attempts and that no participants reported boredom following self-injury. The authors pointed to the potential explanation that self-injury serves a function in alleviating feelings of boredom and emotional numbness. Chapman and Dixon-Gordon (2007) further found that relief was the most common emotional response to self-injury, whereas guilt and anger were the most common emotional responses to ambivalent suicidal attempts and suicidal attempts respectively.

A second area of distinction is risk factors. Risk factors for suicide include broken homes, presence of mental illness in self or family, substance misuse, previous selfinjurious behavior (Hawton \& James, 2005), low self-esteem, female gender, extreme weight control behaviors, early onset of puberty, recent attempts by a friend (Greydanus \& Apple, 2011), conduct problems, non-heterosexual identity (Wichstrom, 2009) and childhood physical abuse (Fuller-Thomson et al., 2012). Established risk factors for selfinjury include abuse, substance misuse, low self-esteem, suicidal ideation, eating disorders (Kakhnovets et al., 2010), early sexual experience, non-heterosexual identity (Wichstrom, 2009), and low income (Toprak et al., 2011). Although there are some similarities (i.e., substance misuse, low self-esteem, suicidal ideation, disordered eating, and non-heterosexual identity) across these risk factors, clear differences exist. For instance, females are much more likely to attempt suicide than males (AAS, 2007; McIntosh, 2008), but recent researchers found that self-injury occurs equally among males and females (Andover et al., 2010; Lloyd-Richardson et al., 2007). Also, the presence of mental illness in one's family and the early onset of puberty have been directly related to increased risk of suicide, but these authors are unaware of any studies 
that establish this link for self-injury. Early sexual experience is also recognized as a risk factor for self-injury, but, to these authors' knowledge, is not regarded as a risk factor for suicide. Those who repeatedly self-injure may be more likely to have a trauma history (Kakhnovets et al., 2010; Kerr \& Muehlenkamp, 2010). Finally, people who repeatedly self-injure are more likely to experience suicidal ideation and substance misuse than those who self-injure only once (Kakhnovets et al., 2010).

Brausch and Gutierrez (2010) studied risk factors and other differences and similarities between self-injury and suicide among 373 high school students. Participants were categorized into three groups: no history of self-injury, non-suicidal self-injury, and self-injury with at least one previous suicide attempt. Participants were measured for differences in depressive symptoms, suicidal ideation, social support, self-esteem, body dissatisfaction, and disordered eating. Rates of $21.2 \%$ for non-suicidal self-injury and $4 \%$ for suicide attempts were identified in the sample. Lower levels of suicidal ideation, anhedonia, and negative self-evaluation were found among participants in the nonsuicidal self-injury group than among the self-injury with suicide attempts group. The non-suicidal self-injury group also reported higher levels of self-esteem and parental support than the self-injury with suicide attempts group. Differences were not identified between the non-suicidal self-injury group and the self-injury with suicide attempts groups on measures of hopelessness, peer support, somatic complaints, and general dysphoria. Based on the results of this study, Brausch and Gutierrez (2010) concluded that anhedonia and negative self-evaluation may more often accompany suicide attempts than non-suicidal self-injury. 
Perspective on life and living is an additional means of distinguishing self-injury from suicide. Muehlenkamp and Gutierrezz (2007) found that those high school students who had attempted suicide reported higher levels of suicidal ideation and depression, along with fewer reasons for living, than those who engaged in self-injury without suicidal attempts. Furthermore, students in the study who reported self-injury without suicidal attempts were able to identify reasons for living, which is antithetical to motivations to end or escape from one's life, as are seen in suicidal attempts.

Although there exists some overlap between self-injury and suicide, wherein those who self-injure are at a heightened risk for suicide (Toprak et al., 2011), self-injury remains largely conceptualized as a means of coping that prevents suicide. Kakhnovets et al., (2010) found that self-injury serves as a coping mechanism for difficult emotions, such as depression, anger, stress, and loss of control. Nock (2009) stated that self-injury “functions as a means both of regulating one's emotional/cognitive experiences and of communicating with or influencing others" (p. 79). So, although the exact distinctions warrant further examination, some mental health practitioners argue for self-injury to be seen as a separate clinical syndrome (e.g., Muehlenkamp, 2005; Pattison \& Kahan, 1983), so much so that "non-suicidal self-injury" is included as a proposed revision to the DSMV (American Psychiatric Association, 2012).

Nock, Prinstein, and Sterba (2010) examined self-injurious thoughts and behaviors among adolescents, through which support for the conceptualization of selfinjury as a coping mechanism was established. Using ecological momentary assessment, Nock et al. (2010) studied the frequency, duration, and intensity of self-injurious and suicidal thoughts among 30 adolescents who reported a history of self-injury. The 
researchers found that non-suicidal self-injurious thoughts occurred with greater intensity than suicidal thoughts, but had a shorter duration than suicidal thoughts. Moreover, duration of thoughts was found to be a less accurate predictor of behavior, compared to the intensity of thoughts. Given that non-suicidal self-injurious thoughts occurred with great intensity, they were likely to be followed by self-injurious behavior. Suicidal thoughts, however, occurred with less intensity and were less likely to be followed by suicidal attempts. A significant finding of this study is that self-injury was rarely accompanied by suicidal thoughts, which enforces the non-suicidal, coping functions of self-injury (Nock et al., 2010).

Additional support for self-injury as a coping mechanism came from a study conducted by Claes et al., (2010). They examined similarities and differences between self-injury and suicide among 128 patients in a Belgium psychiatric facility. The researchers found higher rates of suicidal ideation, neuroticism, depression, and hopelessness among patients who attempted suicide than among patients who self-injured in the absence of suicidal attempts. The researchers also found a difference in patients' reaction patterns to challenging life events. Passive or depressive reaction patterns were reported more frequently among patients who attempted suicide than among patients who self-injured without suicidal attempts, providing evidence that people who attempt suicide tend to have fewer coping skills and reasons for living than those who self-injure without attempting suicide. Further, this study demonstrated that people who self-injure without suicide attempts tend to have more coping strategies and less severe symptoms of depression, neuroticism, and hopelessness (Claes et al., 2010). 
Gilbert et al. (2010) found that critical self-talk, particularly of the persecutory fashion, is linked to self-injury in a sample of inpatient and partial hospitalization patients. Persecutory self-criticism relates to ideas about deserving to suffer or to be punished. Kerr and Muehlenkamp (2010) found similar patterns in their study of college men and women, noting that participants in their study who reported self-injury also provided evidence of a distorted and negative self-image, depressive cognitions, hypervigilance, and disordered thoughts. Accordingly, for those self-injuring clients who present with marked negative self-criticism and distorted thoughts, therapeutic interventions that address maladaptive cognitive patterns, such as cognitive therapy, may be helpful.

Research on self-injury and suicide has identified protective factors. A supportive family can be considered an insulating factor. For example, Toprak et al. (2011) found that adolescents who do not have a good relationship with their family are 13 times more likely to self-injure. Wichstrom's (2009) study of Norwegian high school students supports this finding, identifying parental attachment as an insulating factor against selfinjury and suicide attempts. This finding was echoed by Brausch and Gutierrez (2010), who found evidence to indicate that parental support is a major protective factor against suicide among adolescents who self-injure. Similarly, having a romantic partner may help to protect against self-injury (Toprak et al., 2011) and, particularly for women, having a child can be an insulating factor against suicide (Fazel, Cartwright, Norman-Nott, \& Hawton, 2008).

Researchers (e.g., Klonsky et al., 2011; Nock, 2009) continue to explore the similarities and differences between self-injury and suicide, highlighting some important 
distinctions. The emotional antecedents and consequences of self-injury and suicide differ, with anger decreasing after self-injury but not after suicide attempts (Chapman \& Dixon-Gordon, 2007). Boredom has been identified as an emotional antecedent for selfinjury, but not for suicide attempts. Moreover, relief has been identified as the most common emotional response to self-injury, whereas the most common emotional responses to suicide attempts are guilt and anger. Research on risk factors for self-injury and suicide also points to some interesting similarities and significant differences.

Common risk factors include substance misuse (e.g., Hawton \& James, 2005; Kakhnovets et al., 2010), low self-esteem (e.g., Greydanus \& Apple, 2011; Kakhnovets et al., 2010), suicidal ideation (e.g., Kakhnovets et al., 2010), disordered eating (e.g., Greydanus \& Apple, 2011; Hawton \& James, 2005; Kakhnovets et al., 2010), and nonheterosexual identity (Wichstrom, 2009). A family history of mental illness (Hawton \& James, 2005) and early onset of puberty (Greydanus \& Apple, 2011) have been identified as risk factors for suicide, but may not be related to self-injury. Additionally, early sexual experience has been linked to self-injury (Wichstrom, 2009) but may not be related to suicide. Similarly, a history of trauma is relatively common among people who selfinjure (Kakhnovets et al., 2010; Kerr \& Muehlenkamp, 2010). Those who repeatedly selfinjure tend to experience more suicidal ideation and substance misuse than those who self-injure only once (Kakhnovets et al., 2010). Furthermore, anhedonia and negative self-evaluation have been linked to suicide attempts, but much less so to self-injury (Brausch \& Gutierrez, 2010). Conversely, people who self-injure without attempting suicide reported higher levels of self-esteem and parental support (Brausch \& Gutierrez, 2010). 
The role of gender has also been examined. Although females attempted suicide more frequently than males (AAS, 2007; McIntosh, 2008), there was an equal distribution of self-injury among males and females (Andover et al., 2010; LloydRichardson et al., 2007). Additional differences in perspective on life and living have been identified, wherein people who self-injure reported less suicidal ideation, less depression, and more reasons for living than those who attempt suicide (Muehlenkamp \& Gutierrezz, 2007). The coping function of self-injury to manage difficult emotions (Claes et. al, 2010; Kakhnovets et al., 2010; Nock, Prinstein, \& Sterba, 2010) has been established, supporting the role of self-injury as a means of preventing suicide. Additionally, people who self-injure without attempting suicide tended to have less severe emotional disturbance than those who attempt suicide (Claes et. al, 2010).

\section{Practical Implications for Counselors}

It is essential for professional counselors to understand the functional and conceptual differences between self-injury and suicide in order to provide the most efficacious treatment. Although differences between self-injury and suicide can and should be addressed, the established risk of suicide among people who self-injure (Chapman \& Dixon-Gordon, 2007; Toprak et al., 2011) warrants special consideration. Accordingly, mental health professionals who work with clients who self-injure need to make efforts to assess for suicidal risk. Unfortunately, interpreting the presence of suicidal risk is complicated, in part because the experience of suicidal ideation can itself involve mixed feelings associated with wanting to escape and wanting to live (Maddock, Carter, Murrell, Lewin, \& Conrad, 2010). Janis and Nock (2008) found that, although people's assessment of their future self-injurious thoughts and behavior is correlated with 
their actual future behavior, looking at past self-injurious thoughts and behavior is a better means of ascertaining the most probable course of future behavior. Toprak et. al. (2011) offered similar cautions, noting that those who self-injure and have a history of suicide attempts may underestimate the lethality of their suicide attempts. Accordingly, clinicians may inadvertently and unknowingly, misjudge the level of suicidal risk in these clients (Toprak et al., 2011).

Based on the literature review, we recommend the following for professional counselors who are working with clients who self-injure and experience suicidal thoughts. Janis and Nock (2008) advised that counselors use multiple means of assessing suicidal risk and avoid relying too heavily on client self-report or clinician estimation of risk. Similarly, counselors may pay closer attention to the frequency of self-injurious behavior, because those who self-injure repeatedly are more likely to experience suicidal ideation than those who experience a single episode of self-injury (Kakhnovets et al., 2010). Looking for the presence of critical self-talk, particularly persecutory selfcriticism and messages about deserving to suffer (e.g., Gilbert et al., 2010) and other indications of a distorted self-image (e.g., Kerr \& Muehlenkamp, 2010) may be particularly relevant when working with clients who self-injure. Additionally, taking a trauma history can be very helpful, because clients who self-injure are likely to have experienced past trauma (Kakhnovets et al., 2010). Inquiring into the client's protective factors, particularly the presence of a supportive family (e.g., Toprak et al., 2011; Brausch, \& Gutierrez, 2010; Wichstrom, 2009), intimate partner (e.g., Toprak et al., 2011), and a child (e.g., Fazel et al., 2008) may assist the counselor in assessing risk and working with the client from a strengths-based perspective. And, finally, we suggest 
talking with your clients about their ideas regarding life and living (e.g., Muehlenkamp \& Gutierrezz, 2004). They may want to escape the pain, not necessarily end their lives.

\section{Implications for Future Research}

Research on self-injury and suicide has helped to illuminate their similarities and differences, but much remains unknown about the relationship between these two parasuicidal behaviors (Klonsky et al., 2011). In addition to continued analysis of the personality profiles of persons who experience suicidal ideation and self-injury, future research should examine the conceptual and practical differences between self-injury and suicide. One means of achieving this goal is to gather expert opinion from mental health professionals who have an extensive work history with clients who self-injure.

\section{Summary}

Professional counselors who work with clients who experience suicidal thoughts or self-injury face unique challenges. Because differentiating between suicidal attempts and self-injury is rarely straightforward, these challenges are further complicated when clients present with both comorbidly. Professional counselors working with these populations should be familiar with the sometimes overlapping dimensions of both selfinjury and suicide, while also being able to distinguish between them. In this paper, an overview of self-injury and suicide was provided, followed by a discussion of ways in which they have been differentiated. Discussions of the continuum of self-harm, as well as similarities and differences in risk factors, emotional antecedents and consequences, and client perspective on living were presented. Practical implications for professional counselors were also presented, with special attention to treatment considerations. Issues of client prediction of self-injury and suicide, frequency of self-injury, the presence of 
suicidal ideation and substance misuse, and the roles of trauma and critical self-talk among persons from both populations were discussed. 


\section{References}

Alderman, T. (1997). The scarred soul: Understanding and ending self-inflicted violence. CA, Oakland; New Harbinger,

American Association of Suicidology. (2007). Suicide in the U.S.A.: Based on current (2007) statistics. Retrieved from the American Association of Suicidology website: http://www.suicidology.org/c/document_library/get_file?folderId=248\&name=D LFE-415.pdf

American Psychiatric Association (2012). Proposed revision. In DSM-5 Development. Retrieved from http://www.dsm5.org/ProposedRevisions/Pages/proposedrevision.aspx?rid=443

Andover, M. S., Primack, J. M., Gibb, B. E., \& Pepper, C. M. (2010). An examination of non-suicidal self-injury in men: Do men differ from women in basic NSSI characteristics? Archives of Suicide Research, 14,79-88.

Bebbington, P.E., Minton, S., Cooper, C., Dennis, M., Meltzer, H., Jenkins, R., \& Brugha, T. (2010). Suicidal ideation, self-harm, and attempted suicide: Results from the British psychiatric morbidity survey 2000. European Psychiatry, 25, 427-431.

Brausch, A. M., \& Gutierrezz, P. M. (2010). Differences in non-suicidal suicide and selfinjury attempts in adolescents. Youth Adolescence, 39, 233-242. doi:10.1007/s10964-009-9482-0 
Briere, J., \& Gil, E. (1998). Self-mutilation in clinical and general population samples: Prevalence, correlates, and functions. American Journal of Orthopsychiatry, 68, 609-620.

Chapman, A. L., \& Dixon-Gordon, K. L. (2007). Emotional antecedents and consequences of deliberate self-harm and suicide attempts. Suicide and LifeThreatening Behavior 37(5), 543-552.

Claes, L., Muehlenkamp, J., Vandereycken, W., Hamelinck, L., Martens, H., \& Claes, S. (2010). Comparison of non-suicidal self-injurious behavior and suicide attempts in patients admitted to a psychiatric crisis unit. Personality and Individual Differences, 48, 83-87.

Craigen, L., Healey, A., Walley, C., Byrd, R., \& Schuster, J. (2010). Assessment and self-injury, Implications for counselors. Measurement and Evaluation in Counseling and Development, 43, 3-15.

Evan, J., Evans, M., Morgan, H., Hayward, A., \& Gunnell, D. (2005). Crisis card following self-harm: 12 month follow-up of a randomised controlled trial. The British Journal of Psychiatry. 187,186-187.

Fazel, S., Cartwright, J., Norman-Nott, A., \& Hawton, K. (2008). Suicide in prisoners: A systematic review of risk factors. Journal of Clinical Psychiatry, 69, 1721-1732.

Fuller-Thomson, E., Baker, T. M., \& Brennenstuhl, S. (2012). Evidence supporting an independent association between childhood physical abuse and lifetime suicidal ideation. Suicide and Life-Threatening Behavior. Retrieved from http://onlinelibrary.wiley.com/doi/10.1111/j.1943-278X.2012.00089.x/abstract 
Gilbert, P., McEwan, K., Irons, C., Bhundia, R., Christie, R., Broomhead, C., \& Rockliff, H. (2010). Self-harm in a mixed clinical population: The roles of self-criticism, shame, and social rank. British Journal of Clinical Psychology, 49, 563-576.

Gratz, K. L. (2006). Risk factors for repeated deliberate self-harm among female college students: The role and interaction of childhood maltreatment, emotional inexpressivity, and affect intensity/reactivity. American Journal of Orthopsychiatry, 76(2), 238-250. doi: 10.1037/0002-9432.76.2.238

Greydanus, D. E., \& Apple, R. W. (2011). The relationship between deliberate self-harm behavior, body dissatisfaction, and suicide in adolescents: current concepts. Journal of Multidisciplinary Healthcare, 4, 183-189.

Gunter, T. D., Philibert, R. P., \& Hollenbeck, N. (2009). Medical and psychiatric problems among men and women in a community corrections residential setting. Behavioral Sciences and the Law, 27, 695-711. doi: 10.1002/bsl.887

Haines, J., \& Williams, C. (2003). Coping and problem solving of self-mutilators. Journal of Clinical Psychology, 59(10), 1097-1106.

Hawton, K. \& James, A. (2005). ABC of adolescence: Suicide and deliberate self harm in young people. Clinical Review, 330, 891-894.

Hawton, K. \& Harriss, L. (2008). How often does deliberate self-harm occur relative to each suicide? A Study of Variations by Gender and Age. Suicide and Life Threatening Behavior, 38, 6.

Hawton, K. \& Harriss, L., \& Rodman, K. (2010). How adolescents who cut themselves differ from those who take overdoses. European Child and Adolescent Psychiatry, 19, 513-523. doi: 10.1007/s00787-009-0065-0 
Howson, M. A., Yates, K. M., \& Hatcher, S. (2008). Re-presentation and suicide rates in emergency department patients who self-harm. Emergency Medicine Australasia 20, 322-327. doi: 10.1111

Jacobson, C., \& Gould, M. (2007). The epidemiology and phenomenology of nonsuicidal self-injurious behavior among adolescents: A critical review of the literature. Archives of Suicide Research, 11(2), 129-147. doi:

$10.1080 / 13811110701247602$

Janis, I. B., \& Nock, M. K. (2008). Behavioral forecasts do not improve the prediction of future behavior: A prospective study of self-injury. Journal of Clinical Psychology, 64(10), 1164-1174. doi: 10.1002/jclp.20509

Kakhnovets, R., Young, H. L., Purnell, A., L., Huebner, E., \& Bishop, C. (2010). Selfreported experience of self-injurious behavior in college students. Journal of Mental Health Counseling, 32(4), 309-323.

Kerr, P. L., \& Muehlenkamp, J. (2010). Features of psychopathology in self-injuring female college students. Journal of Mental Health Counseling, 32(4), 290-308.

Klonsky, D., \& Muehlenkamp, J. (2007). Self-injury: A research review for the practitioner. Journal of Clinical Psychology, 63, 1045-1056. doi: 10.1002/jclp.20412

Klonsky, E. D., Muehlenkamp, J. J., Lewis, S. P., \& Walsh, B. (2011). Nonsuicidal selfinjury: Advances in psychotherapy evidence-based practice. Cambridge, MA: Hogrefe Publishing. 
Klonsky, E. D., Oltmanns, T. F., \& Turkheimer, E. (2003). Deliberate self-harm in a nonclinical population: Prevalence and psychological correlates. American Journal of Psychiatry, 160, 1501-1508.

Laye-Gindhu, A., \& Schonert-Reichl, K. (2005). Nonsuicidal self-harm among community adolescents: Understanding the "whats" and "whys" of self-harm. Journal of Youth and Adolescence, 34(5), 447-457. doi: 10.1007/s10964- 005$7262-\mathrm{z}$

Lloyd-Richardson, E. E., Perrine, N., Dierker, L., \& Kelley, M. L. (2007). Characteristics and functions of non-suicidal self-injury in a community sample of adolescents. Psychological Medicine, 37, 1183-1192. doi:10.1017/S003329170700027X

Maddock, G. R., Carter, G. L., Murrell, E. R., Lewin, T. J., \& Conrad, A. M. (2010). Distinguishing suicidal from non-suicidal deliberate self-harm events in women with Borderline Personality Disorder. Australian and New Zealand Journal of Psychiatry, 44, 574-582.

McIntosh, J. L. (2008). U.S.A. suicide: 2008 official final data. Retrieved from the American Association of Suicidology website: http://www.suicidology.org/c/document_library/get_file?folderId=232\&name=D LFE-382.pdf

Moyer, M. (2008). Working with self-injurious adolescents using the safe kit. Journal of Creativity in Counseling, 3(1), 61-67.

Muehlenkamp, J. J. (2005). Self-injurious behavior as a separate clinical syndrome. American Journal of Orthopsychiatry, 75(2), 324-333. doi: 10.1037/00029432.75 .2 .324 
Muehlenkamp, J. J. \& Gutierrezz, P. M. (2004). An investigation of differences between self-injurious behavior and suicide attempts in a sample of adolescents. Suicide and Life-Threatening Behavior, 34, 12-23.

Muehlenkamp, J. J., \& Gutierrezz, P. M. (2007). Risk for suicide attempts among adolescents who engage in non-suicidal self-injury. Archives of Suicide Research, 11, 69-82. doi: 10.1080/13811110600992902

Nock, M. N. (2009). Why do people hurt themselves? New insights into the nature and functions of self-injury. Journal of the Association for Psychological Science, $18(2), 78-83$.

Nock, M. K., \& Favazza, A. R. (2009). Nonsuicidal self-injury: Definition and classification. In M. K. Nock (Ed.), Understanding nonsuicidal self-injury: Origins, assessment, and treatment (pp. 9-18). Washington, DC: American Psychological Association.

Nock, M. K., Prinstein, M. J., Sterba, S. K. (2010). Revealing the form and function of self-injurious thoughts and behaviors: A real-time ecological assessment study among adolescents and young adults. Psychology of Violence, 1, 36-52. doi: 10.1037/2152-0828.1.S.36

Pattison, E. M., \& Kahan, J. (1983). The deliberate self-harm syndrome. American Journal of Psychiatry, 140(7), 867-872.

Poland, S. (2008, February). Self-injury: How to understand and help students who engage in this behavior. District Administration, 44(2), 56.

Polk, E., \& Liss, M. (2009). Exploring the motivations behind self-injury. Counseling Psychology Quarterly, 22, 233-241. 
Rudd, D. M., Berman, A. L., Joiner, T. E., Nock, M. K., Silverman, M. M., Mandrusiak, M. Van Orden, K., \& Witte, T. (2006). Warning signs for suicide: Theory, research, and clinical applications. Suicide and Life-Threatening Behavior 36(3), $255-262$

U.S. Department Health and Human Services, Substance Abuse and Mental Health Services Administration, Office of Applied Studies. (2006). Suicidal thoughts, suicide attempts, major depressive episode, and substance use among adults. Retrieved from http://store.samhsa.gov/product/Suicidal-Thoughts-SuicideAttempts-Major-Depressive-Episode-and-Substance-Use-amongAdults/OASRPT06-34

U.S. Department of Health and Human Services, Substance Abuse and Mental Health Services Administration, Center for Substance Abuse Treatment. (2009a). Addressing suicidal thoughts and behaviors in substance abuse treatment: $A$ Treatment Improvement Protocol (TIP) Series, No. 50: 3, 1. Retrieved from http://store.samhsa.gov/product/TIP-50-Addressing-Suicidal-Thoughts-andBehaviors-in-Substance-Abuse-Treatment/SMA09- 4381

U.S. Department of Health and Human Services, Substance Abuse and Mental Health Services Administration, National Survey on Drug Use and Health (2009b). Suicidal Thoughts and Behaviors among Adults. Retrieved from the SAMHSA website: http://oas.samhsa.gov/2k9/165/SuicideHTML.pdf

U.S. Department of Health and Human Services, Centers for Disease Control and Prevention, National Center for Health Statistics, National Vital Statistics System. 
(2010a). Deaths: Preliminary data for 2008 (DHHS Publication No. (PHS) 20111120). Retrieved from http://www.cdc.gov/nchs/data/nvsr/nvsr59/nvsr59_02.pdf

U.S. Department of Health and Human Services, Substance Abuse and Mental Health Services Administration, Center for Behavioral Health Statistics and Quality, National Survey on Drug Use and Health. (2010b). Suicidal thoughts and behaviors among adults: 2008 and 2009. Retrieved from http://oas.samhsa.gov/2k10/212/SuicidalThoughts.cfm

U.S. Department of Health and Human Services, Centers for Disease Control and Prevention, National Center for Injury Prevention and Control. (2011). Self-harm all injury causes nonfatal injuries and rates per 100,000. Retrieved from http://webappa.cdc.gov/cgi-bin/broker.exe

Toprak, S., Cetin, I., Guven, T., Can, G., \& Demircan, C. (2011). Self-harm, suicidal ideation and suicide attempts among college students. Psychiatric Research, 187, 140-144.

Trepal, H., \& Wester, K. (2007). Self-injurious behaviors, diagnoses, and treatment methods: What mental health professionals are reporting. Journal of Mental Health Counseling, 29, 363-375.

Turner, B. J., Chapman, A. L., \& Layden, B. M. (2012). Intrapersonal and interpersonal functions of non suicidal self-injury: Associations with emotional and social functioning. Suicide and Life-Threatening Behavior 42(1), 36-55.

Van Orden, K. A., Joiner, T. E., Hollar, D. Rudd, M. D., Mandrusiak, M., \& Silverman, M. M. (2006). A test of the effectiveness of a list of suicide warning signs for the public. Suicide and Life-Threatening Behavior 36(3), 272-287. 
Walsh, B. W. (2006). Treating self-injury: A practical guide. NY: Guilford Press.

Weierich, M. R., \& Nock, K. (2008). Posttraumatic stress symptoms mediate the relation between childhood sexual abuse and nonsuicidal self-injury. Journal of Consulting and Clinical Psychology, 76(1), 39-44. doi: 10.1037/0022-006X76.1 .39

Wester, K. L., \& Trepal, H. C. (2005). Working with clients who self-injure: Providing alternatives. Journal of College Counseling, 8, 180-189.

Whisenhunt, J., \& Kress, V. (2012). The Use of Visual Arts in Counseling Clients who Engage in Non-Suicidal Self-Injury. Manuscript under review.

White, V. E., McCormick, L., \& Kelly, B. (2003). Counseling self-injurious clients: Ethical considerations. Counseling and Values, 47(3), 220-229.

Whitlock, J.L., Eckenrode, J.E. \& Silverman, D. (2006). Self-injurious behavior in a college population. Pediatrics, 117(6), 1939-1948. doi: 10.1542/peds.2005-2543

Wichstrom, L. (2009). Predictors of non-suicidal self-injury versus attempted suicide: Similar or different? Archives of Suicide Research, 13, 105-122. doi: $10.1080 / 13811110902834992$

Windfuhr, K., \& Kapur, N. (2011). International perspectives on the epidemiology and aetilogy of suicide and self-harm. In R. C. O'Connor, S. Platt, \& J. Gordon (Eds.), International handbook of suicide prevention: Research, policy, and practice (pp. 28-57). Malden, MA: Wiley-Blackwell. 


\section{CHAPTER 2}

PROFESSIONAL COUNSELORS' CONCEPTUALIZATIONS OF THE RELATIONSHIP BETWEEN SUICIDE AND SELF-INJURY

Self-injury is defined as non-suicidal volitional self-inflicted harm to the body that is not socially sanctioned (Klonsky, Muehlenkamp, Lewis, \& Walsh, 2011; Nock \& Favazza, 2009), whereas suicide attempts involve self-injurious behavior with the intent to die (Claes et al., 2010). Suicide and self-injury are likely among the most anxietyprovoking clinical issues faced by professional counselors. They are fairly common, potentially dangerous, problematic to predict, and challenging to treat (Janis \& Nock, 2008). The fear of losing a client to suicide is likely a reality for every professional counselor. Similarly, self-injury tends to be an evocative topic for both professionals and the general public (White, McCormick, \& Kelly, 2003). Although our understanding of each phenomenon individually has increased in recent years, the nature of the relationship between suicide and self-injury remains relatively unclear (Claes et al., 2010); however, there is an established link between the two - a heightened risk of suicide among those who self-injure (Brausch \& Gutierrez, 2010; Chapman \& DixonGordon, 2007; Toprak, Cetin, Guven, Can, \& Demircan, 2011). Accordingly, the purpose of this study is to explore the relationship between suicide and self-injury. Specifically, we seek to establish a better understanding of the relationship from the perspective of professional counselors who have experience working with clients who self-injure. The results of this study will aid in expanding the knowledge base on self-injury, furthering our understanding of the relationship between suicide and self-injury, and providing professional counselors with practical implications for their work with these clients. 


\section{Review of the Literature}

The literature on suicide and self-injury is relatively limited and often addresses issues of statistical correlations and risk factors. However, some studies have explored the ways in which suicide and self-injury relate and differ, contributing to our emerging understanding of this relationship. These studies have explored character differences, emotional antecedents and consequences, and perspective on life for both suicide and self-injury.

\section{Rates of Suicide to Self-Injury}

The risk of suicide among persons who self-injure is heightened (Toprak et al., 2011). However, only a portion of those who self-injure attempt or complete suicide (Brausch \& Gutierrez, 2010); the rates of self-injury far exceed those of death by suicide. Studies have attempted to define the exact ratio of self-injury to suicide, but a consensus among the data has yet to be reached (Hawton \& Harriss, 2008). In part, this lack of consistency in the data may be attributed to the ways in which self-injury is conceptualized. Specifically, some studies categorize non-suicidal self-injury alongside suicidal attempts, making it difficult to differentiate between the rates of self-injury and suicidal attempts (Klonsky et al., 2011). This is common among European countries, in which the term "deliberate self-harm" is used to describe a variety of self-harm behaviors, regardless of whether suicidal intent is present (Plener, Libal, Keller, Fegert, \& Muehlenkamp, 2009). A study conducted by Hawton and Harriss (2008) illustrated the point. In their review of ten years of hospital data and both local and national suicide statistics, Hawton and Harris (2008) attempted to identify rates of all forms of deliberate self-harm to suicide. They yielded a ratio of 26.2:1. So, for every one death by suicide, 
there were approximately 26.2 persons who engaged in some type of self-injury, which includes potential suicide attempts (Hawton \& Harriss, 2008). A study by Howson, Yates, and Hatcher (2008) examined rates of suicide among persons who sought medical attention for self-inflicted injuries and found a suicide rate of $1.1 \%$. Again, the study did not differentiate between self-inflicted injury with or without the intent to die.

Other investigations have distinguished between self-injury, suicidal ideation, and suicidal attempts and compared the frequency of each. Unfortunately, the results do not provide a consistent pattern in regards to the frequency relationship. For example, in their study of medical and mental health among 330 non-incarcerated criminal offenders, Gunter, Philibert, and Hollenbeck (2009) found that 38\% disclosed suicidal ideation, 17\% stated that they had attempted suicide, and $12 \%$ reported non-suicidal volitional selfinjury. A study by Toprak et al., (2011) produced a different picture of the frequency relationship. Among 600 undergraduate Turkish students, the researchers found a lifetime prevalence rate of $15.4 \%$ for non-suicidal self-injury, $11.4 \%$ for suicidal ideation, and 7.1\% for suicidal attempts (Toprak et al., 2011). A similar study by Kakhnovets, Young, Purnell, Huebner, and Bishop (2010) surveyed over 500 undergraduate and graduate students about their self-injurious and suicidal behavior. Participants in their study indicated a rate of $15.7 \%$ for at least a single episode of non-suicidal self-injury and a rate of $8.5 \%$ for suicidal ideation among those who reported no history of self-injury (Kakhnovets et al., 2010). The rate of suicidal ideation was drastically increased among those who reported one episode of self-injury (31.8\%) and more than one episode of selfinjury (nearly 60\%; Kakhnovets et al., 2010). The differences in rates of suicidal ideation, self-injury, and suicidal attempts between these studies may be attributed to the different 
populations and environmental factors. Additional research is needed to gain a better understanding of the frequency relationship between self-injury and suicidal ideation and attempts.

\section{Differentiating Self-Injury from Suicide}

There exists some debate among the mental health community in regards to the similarities and differences between suicide and self-injury. Some authors argue for a continuum of suicidal behaviors, with suicide attempts at one end and self-injury at some other point along that same continuum (e.g., Brausch \& Gutierrez, 2010). Even among those authors who distinguish self-injury from suicide, self-injury may still be considered a parasuicidal behavior (e.g., Muehlenkamp \& Gutierrezz, 2007). For some authors, selfinjury cannot conceptually or logistically be distinguished from suicidal attempts (e.g., Hawton \& Harris, 2008; Hawton, Harris, \& Rodman, 2010; Hawton \& James, 2005; Howson et al., 2008; Walsh, 2006). Other authors espouse critical differences between suicide and self-injury (e.g., Chapman \& Dixon-Gordon, 2007; Muehlenkamp \& Gutierrezz, 2004; Walsh, 2006; Wester \& Trepal, 2005). Among these differences, authors cite the non-suicidal functions of self-injury, such as distraction, expression of emotion, and regulation of emotion (Chapman \& Dixon-Gordon, 2007). Despite the lack of consensus on a definition or conceptualization of self-injury (Chapman \& DixonGordon, 2007; Nock \& Favazza, 2009), research has supported some distinctions between the two phenomena.

Klonksy et al., (2011) discussed four primary differences between suicide and self-injury — intent, medical damage, frequency, and means. As aforementioned, selfinjury involves a non-lethal intent, whereas suicide involves the intent to die as a result of 
the behavior. Additionally, in the case of self-injury, physical damage to the body is characteristically less severe than the medical damaged incurred during suicide attempts and is typically not life threatening. Moreover, the frequency of self-injurious acts tends to far outnumber the frequency of suicide attempts. Finally, when comparing people who self-injure to those who attempt or complete suicide, the methods with which a person self-injures tended to be more varied (e.g., cutting, burning, scraping, carving) than the methods by which a person attemptes or completes suicide (Klonsky et al., 2011).

A common differentiation between self-injury and suicide is the conceptualization of self-injury as a coping skill. Kakhnovets et al., (2010) conducted a study among college students and found that self-injury served as a means of coping with complex and intense emotions, such as anger, stress, depression, and loss of control. Nock (2009) echoed these results by stating that self-injury "functions as a means both of regulating one's emotional/cognitive experiences and of communicating with or influencing others" (p. 79). These findings support previous literature, which identified five typical functions of self-injury: emotion regulation, feeling generation, self-punishment, interpersonal influence, and interpersonal communication (Klonsky \& Muehlenkamp, 2007; Turner, Chapman, \& Layden, 2012).

Nock, Prinstein, and Sterba (2010) used ecological momentary assessment to examine the self-injurious thoughts and behaviors of 30 adolescents who reported a history of self-injury. They found that, although non-suicidal self-injurious thoughts occurred with greater intensity than suicidal thoughts, suicidal thoughts had a longer duration than non-suicidal self-injurious thoughts. Additionally, they found that the intensity of the thoughts was a better predictor of the behavior than was the duration of 
the thoughts. A noteworthy finding of this study is that the presence of suicidal thoughts rarely accompanied self-injury. This finding supports the conceptualization of self-injury as a means of coping with rumination and negative events (Nock et al., 2010).

In their study of 128 inpatient admissions to a Belgium psychiatric hospital, Claes et al., (2010) examined similarities and differences between suicide and self-injury. They found that patients who attempted suicide experienced higher rates of depression, hopelessness, suicidal ideation, and neuroticism than those who self-injured without suicidal attempts. Additionally, patients who attempted suicide reported a passive or depressive reaction pattern to difficult life events more frequently than did those who self-injured without suicidal attempts, again highlighting the potential coping function of self-injury (Claes et al., 2010).

Research on the emotional antecedents and consequences of suicide and selfinjury has also helped shed light on some important distinguishing characteristics. Chapman and Dixon-Gordon (2007) surveyed 117 female inmates about their experiences prior to and after engaging in each act. They found that anger was an emotional antecedent for self-injury, suicidal attempts, and ambivalent suicidal attempts. Among those participants who self-injured, anger was reported to have markedly decreased following the self-injurious episode. This was not true for those participants who had attempted suicide, who actually reported an increase in anger. Boredom was identified as an emotional antecedent for self-injury, with no participants reporting boredom following the self-injurious episode. Boredom was also established as an emotional antecedent for suicidal attempts and ambivalent suicidal attempts, but to a much lesser degree. This study found that relief was the most frequent emotional 
response to self-injury, whereas guilt was the most common emotional response to ambivalent suicidal attempts and anger was the most common emotional response to suicidal attempts (Chapman \& Dixon-Gordon, 2007).

Muehlenkamp and Gutierrezz (2007) identified an additional distinguishing factor-perspective on life. They surveyed high school students and found that rates of suicidal ideation and depression were elevated, with fewer reasons for living, among those students who had attempted suicide compared to those who reported self-injury without suicidal attempts. And, interestingly, those students who reported self-injury in the absence of suicidal attempts identified reasons for living. The ability to name reasons for living does not indicate motivations to end one's life, as is characteristic of suicidal attempts (Muehlenkamp \& Gutierrezz, 2007). A study of 665 German ninth grade students conducted by Plener et al. (2009) supported the finding that suicidal ideation is more prominent among people who self-injure and have previously attempted suicide than among those who self-injure without a previous suicide attempt.

A major distinction between suicide and self-injury relates to the risk factors for each. Risk factors for suicide are numerous and include suicidal thoughts or ideation (Rudd et al., 2006), broken homes, mental illness in self or family members, substance misuse, history of self-injurious behavior (Hawton \& James, 2005), low self-esteem, female gender, risky weight control behaviors, early onset puberty, recent attempts by a friend (Greydanus \& Apple, 2011), behavioral problems, and non-heterosexual identity (Wichstrom, 2009). Sometimes overlapping and sometimes distinct, risk factors for selfinjury include history of or current abuse, substance misuse, low self-esteem, suicidal ideation, eating disorders (Kakhnovets et al., 2010), early first sexual encounter, non- 
heterosexual identity (Wichstrom, 2009), and low socio-economic level (Toprak et al., 2011). Among these, common risk factors to both suicide and self-injury include substance misuse, low self-esteem, suicidal ideation, disordered eating, and nonheterosexual identity. Despite these similarities in risk factors, some distinctions exist. For instance, recent researchers have found equal rates of self-injury among males and females (Andover, Primack, Gibb, \& Pepper, 2010; Lloyd-Richardson, Perrine, Dierker, $\&$ Kelley, 2007), but the rates of suicide attempts among females far surpass those among males (AAS, 2007; McIntosh, 2008). Additionally, early onset of puberty and the presence of mental illness in one's family have been linked to an increased risk of suicide, but the authors were unable to locate a study to indicate the same connection to self-injury. Conversely, early sexual experience has been linked to a heighted risk of selfinjury, but the authors did not locate a study that established the same link for suicide.

A study conducted by Brausch and Gutierrez (2010) examined differences and similarities between suicide and self-injury, among which established risk factors were included. In this study, 373 high school students were divided based on self-report into three groups: no history of self-injury, non-suicidal self-injury, and self-injury with at least one previous suicide attempt. Based on their responses on eight separate self-report inventories, participant groups were measured for differences in depressive symptoms, suicidal ideation, social support, self-esteem, body dissatisfaction, and disordered eating. The authors found rates of $21.2 \%$ for non-suicidal self-injury and $4 \%$ for suicide attempts. Participants in the non-suicidal self-injury group reported lower levels of suicidal ideation, anhedonia, and negative self-evaluation than the self-injury with suicide attempts group. Additionally, the non-suicidal self-injury group reported higher levels of 
parental support and self-esteem than the self-injury with suicide attempts group. The study did not identify differences between these two groups on measures of hopelessness, peer support, somatic complaints, and general dysphoria. These results indicate that anhedonia and negative self-evaluation may be more often implicated in suicide attempts than in non-suicidal self-injury (Brausch, \& Gutierrez, 2010).

Although the specific distinctions between suicide and self-injury require further study, there exists research to support a separation of the two. The heightened risk of suicide among those who self-injure (Toprak et al., 2011) points to a relationship between the two phenomena, the nature of which remains unclear. Additional research that explores this relationship is warranted. Therefore, the purpose of this study is to explore how advanced clinicians conceptualize the relationship between suicide and self-injury. Moreover, this study seeks to understand how the presence of self-injury alters clinical assessment as it relates to suicide risk assessment, how the presence of self-injury alters clinical assessment in general, and how the presence of self-injury alters clinical intervention.

\section{Method}

\section{Participants}

Eligible participants included fully licensed professional counselors who have experience working with clients who self-injure. All participants were administered the Supervisee Levels Questionnaire-Revised (SLQ-R) in an effort to identify those participants who possess advanced counseling skill (i.e., levels 3 and 3i). Scores on the highest levels of the SLQ-R are considered indicators of advanced counseling skill and ability (McNeill, Stoltenberg, \& Romans, 1992). Clinicians who score in level 3 of the 
SLQ-R tend to function autonomously in their professional work with a high degree of confidence, be self-reflective and empathic, maintain consistent motivation in their professional work, and "understand the limitations and complexities of the counseling process" (McNeill et al., 1992, p. 505). Level 3i on the SLQ-R is considered an integrative level, wherein clinicians experience an integration of their clinical skills across the domains of self and other awareness, motivation, and dependency-autonomy (McNeill et al., 1992). Only participant responses for those who scored in level 3 or $3 \mathrm{i}$ on the SLQ-R were included in the data analysis. Similar studies have used peer identification as a means of defining "expert" (e.g., Luborsky, McClellan, Woody, O’Brien, \& Auerbach, 1985; Rubel \& Atieno Okech, 2009). However, the use of peer identification would have required snowball sampling and, thereby, could have reduced the overall number of participants. Accordingly, we sought a means of operationalizing a definition of "advanced clinician."

In determining the number of participant responses to use in the data analysis, we referred to Francis et al., (2010), who emphasize saturation of data over sample size. Francis et al. propose a structure through which data can be coded so as to identify when saturation of data occurs. This begins with determining, at onset, the initial quantity of responses to be analyzed. Remaining data is then coded at specified intervals until new codes no longer emerge. At this point, coding continues for a specified number of responses so as to ensure saturation. In the present study, saturation was achieved at response number 26. Consistent with Francis et al., an additional five interviews were coded to ensure saturation and all coding ceased after number 31. 
Participants were recruited via national, regional, and state professional counseling list serves and, as such, were not defined to a single geographical area of the United States. A total of 31 licensed professional counselors participated in this study. A majority were female $(\mathrm{N}=22)$ and ages ranged from the 26-30 to the 61-65 categories, with the highest proportions among the 31-35 $(\mathrm{N}=6)$ and 36-40 $(\mathrm{N}=8)$ age ranges (Table 1). One participant self-reported as "Caucasian Hispanic," four as African American/Black, and 26 as White/Caucasian/European American. Participants included master's level counselors $(\mathrm{N}=17)$, counselors with a specialist's degree $(\mathrm{N}=4)$, and doctoral level counselors $(\mathrm{N}=10)$. Years licensed as a professional counselor ranged from less than one year to 26 years $(M=9)$. Work settings represented include college counseling $(\mathrm{N}=8)$, private practice $(\mathrm{N}=6)$, community mental health $(\mathrm{N}=7)$, and other $(\mathrm{N}=10)$.

\section{Procedures}

The use of online technology to conduct qualitative research can assist in providing a broader sample and increasing participant honesty when discussing sensitive topics (Balden \& Wittman, 2008). Accordingly, in an effort to attain a larger and more diverse participant sample, an online survey was used as the method of data collection in Table 1

Demographic Distribution of the Sample

Mean Median $\quad$ Range $\quad$ Standard Deviation

Age

26-30 to $61-65$

Years Licensed

9

13.25

$<1 \mathrm{yr}$ to $26 \mathrm{yrs} \quad 7.67$ 
this study. O’Grady and Richards (2010) and Reynolds (2011) used similar designs to examine the role of inspiration in the helping professions and to explore the experiences of faculty who teach courses in multicultural counseling. Participants were recruited by means of an email invitation to participate in an online survey. Email invitations were sent to professional colleagues of the researchers and to professional counseling list serves. All responses were anonymous; identifying information was not collected in the survey, nor were IP addresses tracked.

\section{Instruments}

Supervisee Levels Questionnaire-Revised (McNeill, Stoltenberg, \& Romans, 1992). The SLQ-R is a short 30-item inventory. The SLQ-R, based on the Integrated Developmental Model (IDM), was developed by Stoltenberg, McNeill, and Delworth (1998). It conceptualizes counselor development across three dimensions and four stages. According to the IDM, counselor development occurs across the dimensions of self and other awareness, motivation, and dependency-autonomy (McNeill et al., 1992). As counselors gain skills across these three dimensions, they progress through the four developmental levels. For the purposes of this study, composite scores were used and a minimum cut-off score of 142.5 for level 3 was established. This is consistent with the findings of McNeill et al., (1992), who identified 95\% confidence intervals for all levels of the SLQ-R.

As a test of reliability of the three subscales, Cronbach alpha reliability coefficients were calculated (McNeill et al., 1992). The resulting reliability estimates were .83 for Self and Other Awareness, .74 for Motivation, .64 for DependencyAutonomy, and .88 for the total scores. Construct validity tests of the SLQ-R measured 
differences in subscale and total scores between the three groups-beginning, intermediate, and advanced. Significant correlation was found among the following subscales: Self and Other Awareness and Dependency-Autonomy, $r=.53 p<.001$; Self and Other Awareness and Motivation, $\mathrm{r}=.58 \mathrm{p}<.001$; and Motivation and DependencyAutonomy, $\mathrm{r}=.43 \mathrm{p}<.001$. However, an analysis of variance (ANOVA), using trainee experience as the independent variable, indicated a statistically significant difference between the three groups on total SLQ-R scores, $\mathrm{F}(2,102)=7.37 \mathrm{p}<.00$. Further, using a .05 alpha level, significant differences in mean subscale and total SLQ-R scores were found between all the groups except the beginning and intermediate groups.

Demographic Sheet and Open Ended Questions. Participants were asked to provide basic demographic information and respond to the following seven open-ended questions: 1) Thinking of your work with clients who self-injure versus those who do not self-injure, do you believe that clients who self-injure have a different relationship with suicide than those who do not self-injure? Please explain, 2) Thinking of your work with clients who self-injure versus those who do not self-injure, do you believe that clients who self-injure are at a heightened risk of suicide versus those who do not self-injure? Please explain, 3) Thinking of your work with clients who self-injure versus those who do not self-injure, do you assess differently for suicidal risk in your clients who selfinjure than with clients who do not self-injure? Please explain, 4) Does the presence of self-injury impact your treatment goals? Please explain, 5) Does the presence of selfinjury impact how you work with these clients? Please explain, 6) What are some general guidelines you follow when you work with clients who self-injure versus those clients 
who do not self-injure? Please explain, and 7) How do you determine whether your clients self-injure? Please explain.

These questions were developed in collaboration with five individuals which included two practicing clinicians, two counselor educators, and one methodologist. The questions were developed with the intention of not assuming a relationship between suicide and self-injury since a clear relationship has not yet been established in the literature (i.e., Nock \& Favazza, 2009). Question one asks participants to speak directly to their ideas about whether a relationship between suicide and self-injury exists. Question two addresses the documented risk of suicide among clients who self-injure (i.e., Brausch \& Gutierrez, 2010, Chapman \& Dixon-Gordon, 2007; Toprak et al., 2011) and whether professional counselors perceive an increased risk. In consideration of the lack of clarity surrounding differences and similarities between suicide and self-injury (e.g., Brausch \& Gutierrez, 2010; Hawton \& Harris, 2008; Hawton et al., 2010; Hawton \& James, 2005; Howson et al., 2008), the third question was designed to examine whether the presence of self-injury impacts suicide risk assessment. Similarly, in question four, we sought to address whether self-injury was distinguished as a separate treatment goal for counselors. Considering the limited literature available on best practice for working with clients who self-injure (i.e., Wester \& Trepal, 2005), questions five and six were designed to examine how self-injury may or may not affect the counseling relationship and impact treatment interventions. The final question addresses one that is overlooked in the literature- how counselors determine whether or not self-injury is present. 


\section{Research Team}

The use of a coding team can assist in creating a richer set of codes and increase coding reliability (Saldana, 2009). Accordingly, the present study utilized a coding team comprised of three licensed professional counselors. Weston et al., (2001) emphasized the importance of considering the structure of the research team and the influence each member brings to the study. All three team members are female. Two self-identify as White/Caucasian and one as biracial Native American and White. The age of the coders was 24,33 , and 42 at the time of the study. Two of the coders were doctoral students in counselor education, and the third coder was finishing her specialist's degree in professional counseling at the time of the data analysis. All three coders had experience working with clients who self-injure prior to conducting the study, with the greatest experience among the two doctoral student coders — one of whom is a traumatologist. Inclusion of the traumatologist was intentional, in consideration of her extensive work with clients who self-injure. Inclusion of the specialist's student was a purposeful attempt to help minimize researcher bias, as the respective coder had less clinical experience with clients who self-injure and presumably less assumptions about the population.

\section{Data Analysis}

SLQ-R. A total of 35 people participated in this study. However, four participants did not meet the minimum inclusion criteria and, thus, their responses were not used in the data analysis. The range of SLQ-R scores for the remaining 31 responses was 145 to 187, with a mean score of 167.7 and a standard deviation of 8.89 (Table 2). Cronbach's alpha for the 30 SLQ-R items was .663 (Table 3). This analysis reflects a correction to 
Table 2

Scale Statistics for SLQ-R Responses

Mean Variance Std. Deviation N of Items

$\begin{array}{llll}167.7000 & 79.045 & 8.89072 & 30\end{array}$

Table 3

Cronbach's Alpha for SLQ-R Responses

Cronbach's Alpha N of Items

$.663 \quad 30$

the data for 18 responses, in which a null score of one was used for item number two on the SLQ-R to correct for an error in the survey administration.

Qualitative content analysis. Data collected in this study was analyzed using qualitative content analysis (e.g., Schreier, 2012). This inductive method of analysis is recommended when a formal theory about the research topic is unavailable or the present knowledge is fragmented (Hsieh \& Shannon, 2005; Lauri \& Kyngas, 2005). In this sense, qualitative content analysis provides a means through which to generate knowledge of a phenomenon rather than to confirm existing knowledge (Elo \& Kyngas, 2008).

Accordingly, qualitative content analysis emphasizes an avoidance of pre-existing categories and instead the generation of new categories (Hsieh \& Shannon, 2005). The overarching goal of qualitative content analysis is to "systemically describe the meaning of your material" (Scheier, 2012, p. 3).

The procedure of qualitative content analysis involves multiple steps, but can succinctly be described as a process of deriving categories and subcategories from a unit 
of analysis, such as an interview or written statement (Elo \& Kyngas, 2008). These categories are then organized into a hierarchal structure that describes the nature of their relationship (Hsieh \& Shannon, 2005). Definitions are established and examples are identified for each category and subcategory. Within this coding and categorization process, either manifest or latent content can be coded (Elo \& Kyngas, 2008). The present study involved coding of latent content, which is characteristic of qualitative content analysis (Schreier, 2012). This means that the analysis of the data involved a process of meaning making beyond that which was "immediately obvious" or "literal" within the data.

Data analysis in this study followed the structure for inductive qualitative content analysis described by Scheier (2012). This process began with all three coders independently coding an initial data set. A research team meeting was held to compare and discuss the initial codes, resulting in the development of a codebook or coding frame (Scheier, 2012). At the time of developing the initial code book, preliminary categories, subcategories, definitions, and examples were established. This code book was datadriven, meaning that the categories and subcategories were derived from the data, as opposed to being derived from pre-existing concepts and literature (Scheier, 2012). Data set number one was recoded with the initial codebook to verify its accuracy to the data. A second data set was subjected to a pilot test of the codebook. The coding team reconvened to discuss the pilot test and revisions to the codebook were made, after which it was considered ready for use. Subsequent data sets were then coded independently by two research team members using the code book and verified by a third research team member. The code book was continually modified to accommodate emerging codes. 
Initial code sets were then recoded with the final code book. A coding team meeting was held to determine whether any categories or subcategories should be condensed and to discuss interpretation of the results.

\section{Trustworthiness}

Multiple measures were taken to increase the trustworthiness of this study.

Reflexivity in data interpretation was used by means of an ongoing research journal kept by the student principal investigator. The research journal functions as a means through which to document and reflect on emerging ideas, including interpretation of the data and personal reactions, throughout the research process (Saldana, 2009). An external auditor reviewed this journal for the presence of researcher bias in data interpretation. In addition, the external auditor verified the accuracy of all SLQ-R scores and, as mentioned below, reviewed the final codebook.

Coding and analysis procedures in this study were designed to reduce the impact of the researchers' preconceptions and expectations. Data was coded by a team of three coders, so that no single piece of data was reviewed by only one coder. This process of "double coding" is one of the most important means of increasing trustworthiness when conducting qualitative content analysis, as it diminishes researcher bias and increases the reliability of codes (Schreier, 2012, p. 16). As part of the double coding process, an ongoing codebook was developed and revised as necessary by the coding team. The final codebook and analysis were also subjected to an external audit, wherein the auditor reviewed categories and subcategories for unidimensionality and mutual exclusivity. As described by Scheier (2012), unidimensionality indicates that each category and subcategory capture only one aspect of the data. Mutual exclusivity refers to the idea that 
each category and subcategory should reflect ideas that are separate from the others, such that there is no overlap in the concepts they reflect. Consistent with the process of inductive qualitative content analysis and as a means of increasing validity, the analysis was subjected to a comparison to existent relevant literature. Points of divergence from the literature were noted and re-evaluated to determine if the divergence was reflected in the actual data or was the result of researcher bias in coding.

\section{Results}

\section{Relationship between Suicide and Self-Injury}

Qualitative content analysis of the data yielded seven categories and 27 supporting subcategories (Table 4). These categories and subcategories were not exclusive, meaning that a single participant response may include data that was coded into different, sometimes contrasting, categories and/or subcategories (Table 5). Both the number of participants $(\mathrm{N})$ whose statements were coded into a category or subcategory and the number of times a subcategory was coded (frequency count) will be presented.

The category relationship between suicide and self-injury $(\mathrm{N}=19)$ includes subcategories that speak to participants' ideas regarding whether suicide and self-injury are related. It includes the subcategories suicide and self-injury are unrelated, suicide and self-injury are related, and relationship is unclear. The subcategory suicide and selfinjury are unrelated $(\mathrm{N}=12$; frequency $=13)$ is defined as "participants express the idea that suicide and self-injury are unrelated or serve different purposes." Examples of this subcategory include "self-injury is essentially a life preserving effort rather than a life ending effort" and "the typical rationale for suicide is often different than the typical rationale for self-injury." Coding within the subcategory suicide and self-injury are 
Table 4

Categories, Subcategories, Frequency Counts, and Definitions

\begin{tabular}{|c|c|c|}
\hline Category & $\begin{array}{l}\text { Subcategories } \\
\text { (frequency counts) }\end{array}$ & Definitions \\
\hline \multirow[t]{3}{*}{$\begin{array}{l}\text { Relationship between } \\
\text { Suicide and SI }\end{array}$} & $\begin{array}{l}\text { SI and suicide are } \\
\text { unrelated (13) }\end{array}$ & $\begin{array}{l}\text { Participants express the idea that } \\
\text { suicide and SI are unrelated or serve } \\
\text { different purposes. }\end{array}$ \\
\hline & $\begin{array}{l}\text { SI and suicide are } \\
\text { related (7) }\end{array}$ & $\begin{array}{l}\text { Participants express the idea that } \\
\text { suicide and SI are related in some } \\
\text { way. }\end{array}$ \\
\hline & $\begin{array}{l}\text { Relationship is } \\
\text { unclear (3) }\end{array}$ & $\begin{array}{l}\text { Participants express the idea that the } \\
\text { relationship between SI and suicide } \\
\text { is unclear or uncertain. }\end{array}$ \\
\hline \multirow[t]{4}{*}{ Functions of SI } & $\begin{array}{l}\text { SI as emotional } \\
\text { release (6) }\end{array}$ & $\begin{array}{l}\text { Participants express the idea that SI } \\
\text { serves as a form of emotional } \\
\text { release, relief, or expression of } \\
\text { emotion. }\end{array}$ \\
\hline & $\begin{array}{l}\text { SI as emotion } \\
\text { regulation }(8)\end{array}$ & $\begin{array}{l}\text { Participants express the idea that SI } \\
\text { is a means of regulating emotion. }\end{array}$ \\
\hline & $\begin{array}{l}\text { SI as a negative } \\
\text { coping skill ( } 7 \text { ) }\end{array}$ & $\begin{array}{l}\text { Participants express the idea that SI } \\
\text { is a coping skill, but make reference } \\
\text { to it as an unhealthy or problematic } \\
\text { behavior. }\end{array}$ \\
\hline & $\begin{array}{l}\text { SI as a coping } \\
\text { skill (5) }\end{array}$ & $\begin{array}{l}\text { Participants express the idea that SI } \\
\text { is a means of coping, without } \\
\text { specifying it as negative or } \\
\text { maladaptive. }\end{array}$ \\
\hline \multirow[t]{3}{*}{ Associated Risk } & $\begin{array}{l}\text { Suicide is not the } \\
\text { intention (17) }\end{array}$ & $\begin{array}{l}\text { Participants express the idea SI is not } \\
\text { intentionally suicidal in nature or } \\
\text { equivalent to a suicide attempt. }\end{array}$ \\
\hline & Higher risk (34) & $\begin{array}{l}\text { Participants express the idea that } \\
\text { there exists a higher safety risk with } \\
\text { clients who SI. This may be related } \\
\text { to fatal or nonfatal physical harm. }\end{array}$ \\
\hline & $\begin{array}{l}\text { SI does not increase } \\
\text { suicide risk (9) }\end{array}$ & $\begin{array}{l}\text { Participants express the idea that SI } \\
\text { does not necessarily increase risk. } \\
\text { Participants may speak to other risk } \\
\text { factors as better indicators of the } \\
\text { degree of risk. }\end{array}$ \\
\hline Suicide Risk Assessment & $\begin{array}{l}\text { Unmodified suicide } \\
\text { risk assessment (22) }\end{array}$ & $\begin{array}{l}\text { Participants state that they do not } \\
\text { assess for suicide risk differently } \\
\text { with clients who SI than with clients } \\
\text { who do not SI. }\end{array}$ \\
\hline
\end{tabular}




\begin{tabular}{|c|c|c|}
\hline Category & $\begin{array}{l}\text { Subcategories } \\
\text { (frequency counts) }\end{array}$ & Definitions \\
\hline & $\begin{array}{l}\text { Modified suicide } \\
\text { risk assessment (27) }\end{array}$ & $\begin{array}{l}\text { Participants state that they assess } \\
\text { differently for suicide risk with } \\
\text { clients who SI than with clients who } \\
\text { do not SI. }\end{array}$ \\
\hline \multirow[t]{4}{*}{$\begin{array}{l}\text { Treatment Planning } \\
\text { and Goals }\end{array}$} & $\begin{array}{l}\text { Specific treatment } \\
\text { plan }(20)\end{array}$ & $\begin{array}{l}\text { Participants state that their treatment } \\
\text { plan with clients who SI includes } \\
\text { specific inclusion of SI. }\end{array}$ \\
\hline & $\begin{array}{l}\text { Replacing behaviors } \\
\text { (11) }\end{array}$ & $\begin{array}{l}\text { Participants state that they work with } \\
\text { the client to replace SI behaviors } \\
\text { with either alternatives to SI or other } \\
\text { coping skills. }\end{array}$ \\
\hline & $\begin{array}{l}\text { Unmodified } \\
\text { treatment plan (2) }\end{array}$ & $\begin{array}{l}\text { Participants state that their treatment } \\
\text { of clients who SI does not differ } \\
\text { markedly from their treatment of } \\
\text { other similar clinical issues. }\end{array}$ \\
\hline & $\begin{array}{l}\text { Comorbid treatment } \\
\text { considerations }(11)\end{array}$ & $\begin{array}{l}\text { Participants talk about comorbid } \\
\text { issues that impact treatment and/or } \\
\text { may be a focus for treatment. }\end{array}$ \\
\hline \multirow[t]{6}{*}{ Intervention } & $\begin{array}{l}\text { Client directed } \\
\text { treatment (12) }\end{array}$ & $\begin{array}{l}\text { Participants state that they do not } \\
\text { impose their expectations or goals } \\
\text { related to SI onto the client. }\end{array}$ \\
\hline & $\begin{array}{l}\text { Counselor concern } \\
\text { (5) }\end{array}$ & $\begin{array}{l}\text { Participants express concern for the } \\
\text { client's safety and/or concern for self } \\
\text { in regards to professional liability. }\end{array}$ \\
\hline & $\begin{array}{l}\text { SI as an ongoing } \\
\text { treatment } \\
\text { consideration }(3)\end{array}$ & $\begin{array}{l}\text { Participants express the idea that } \\
\text { treatment of SI is an ongoing issue } \\
\text { that is attended to throughout the } \\
\text { therapeutic relationship. }\end{array}$ \\
\hline & $\begin{array}{l}\text { Specific interventions } \\
(37)\end{array}$ & $\begin{array}{l}\text { Participants talk about specific } \\
\text { interventions they use, which are } \\
\text { tailored to the client who self-injures. }\end{array}$ \\
\hline & $\begin{array}{l}\text { Unmodified } \\
\text { interventions (5) }\end{array}$ & $\begin{array}{l}\text { Participants state that their work with } \\
\text { clients who SI does not differ from } \\
\text { their work with clients for whom SI } \\
\text { is not a known concern. }\end{array}$ \\
\hline & Normalize SI (5) & $\begin{array}{l}\text { Participants express the idea that SI } \\
\text { needs to be normalized in the } \\
\text { therapeutic relationship, making it } \\
\text { less shameful, taboo, or secret. }\end{array}$ \\
\hline
\end{tabular}




\begin{tabular}{lll}
\hline Category & $\begin{array}{l}\text { Subcategories } \\
\text { (frequency counts) }\end{array}$ & Definitions \\
\hline $\begin{array}{l}\text { Client centered } \\
\text { therapeutic } \\
\text { relationship (11) }\end{array}$ & $\begin{array}{l}\text { Participants talk about specific } \\
\text { aspects of or modifications to the } \\
\text { therapeutic relationship that make } \\
\text { working with this population more } \\
\text { effective. }\end{array}$ \\
\hline & $\begin{array}{l}\text { Supervision/ } \\
\text { Consultation/ } \\
\text { Collaboration (7) }\end{array}$ & $\begin{array}{l}\text { Participants talk about the } \\
\text { importance of clinical supervision, } \\
\text { consultation, and/or collaboration } \\
\text { with other medical or mental health } \\
\text { professionals in their work with } \\
\text { clients who SI. }\end{array}$ \\
\hline Identification of SI & $\begin{array}{l}\text { Participants state that they identify } \\
\text { SI through direct client self- } \\
\text { disclosure. }\end{array}$ \\
\hline $\begin{array}{ll}\text { through client self- } \\
\text { disclosure (9) }\end{array}$ & $\begin{array}{l}\text { Participants state that they identify } \\
\text { through observation }\end{array}$ & $\begin{array}{l}\text { SI through observation of the client, } \\
\text { his/her behavior, and/or visible signs } \\
\text { of SI. }\end{array}$ \\
\hline (19) & $\begin{array}{l}\text { Identification through Participants state that they identify } \\
\text { direct questioning } \\
\text { SI through directly asking the client. }\end{array}$ \\
\hline
\end{tabular}

related $(\mathrm{N}=5$; frequency $=7$ ) required that "participants express the idea that suicide and self-injury are related in some way." Examples of relevant codes include "persons who self-injure are more likely to contemplate, attempt, and complete suicide," "I believe that they do have a different relationship with suicide because with the ones I have worked with they were not uncomfortable with the idea of suicide as I have seen other non-self-injury clients be," and "yes, mostly because they generally have deep seeded depression they are working against." The subcategory relationship is unclear $(\mathrm{N}=2$; frequency $=3$ ) is characterized by participant responses that "express the idea that the relationship between self-injury and suicide is unclear or uncertain." Examples include "there are those who self-injure who also have suicidal ideation and planning. However, 
Table 5

Response Exclusiveness and Inclusiveness

\begin{tabular}{|c|c|}
\hline Category & Subcategories/Participant ID \\
\hline \multirow[t]{3}{*}{ Relationship between Suicide and SI } & $\begin{array}{l}\text { SI and suicide are unrelated } \\
304,307,308,310,312,314,317,322,326,332,343,344\end{array}$ \\
\hline & $\begin{array}{l}\text { SI and suicide are related } \\
323,329,335,337,355\end{array}$ \\
\hline & $\begin{array}{l}\text { Relationship is unclear } \\
346,349\end{array}$ \\
\hline \multirow[t]{4}{*}{ Functions of SI } & $\begin{array}{l}\text { SI as emotional release } \\
304,312,322,330,346,349\end{array}$ \\
\hline & $\begin{array}{l}\text { SI as emotion regulation } \\
307,308,310,315,325,330\end{array}$ \\
\hline & $\begin{array}{l}\text { SI as a negative coping skill } \\
307,312,322,335,347,348\end{array}$ \\
\hline & $\begin{array}{l}\text { SI as a coping skill } \\
341,345,348,349\end{array}$ \\
\hline \multirow[t]{3}{*}{ Associated Risk } & $\begin{array}{l}\text { Suicide is not the intention } \\
304,306,314,317,322,325,329,330,335,345,346,347,348,351,357\end{array}$ \\
\hline & $\begin{array}{l}\text { Higher risk } \\
304,306,308,310,312,314,315,317,323,324,325,329,330,336,337,341,344 \text {, } \\
345,346,355\end{array}$ \\
\hline & $\begin{array}{l}\text { SI does not increase suicide risk } \\
326,330,332,343,344,348,349,355,357\end{array}$ \\
\hline \multirow[t]{2}{*}{ Suicide Risk Assessment } & $\begin{array}{l}\text { Unmodified suicide risk assessment } \\
304,307,312,317,324,329,330,332,336,341,344,345,346,348,349,357\end{array}$ \\
\hline & $\begin{array}{l}\text { Modified suicide risk assessment } \\
306,310,314,315,317,323,325,326,330,337,343,344,346,347,348,349,351 \text {, } \\
355\end{array}$ \\
\hline \multirow[t]{4}{*}{ Treatment Planning and Goals } & $\begin{array}{l}\text { Specific treatment plan } \\
304,306,307,308,310,314,317,322,323,324,325,326,336,337,344,345,346 \text {, } \\
347,349\end{array}$ \\
\hline & $\begin{array}{l}\text { Replacing behaviors } \\
304,307,314,317,323,324,329,343,345,348,349,355,357\end{array}$ \\
\hline & $\begin{array}{l}\text { Unmodified treatment plan } \\
317,351\end{array}$ \\
\hline & $\begin{array}{l}\text { Comorbid treatment considerations } \\
322,329,330,343,344,346,349\end{array}$ \\
\hline \multirow[t]{8}{*}{ Intervention } & $\begin{array}{l}\text { Client directed treatment } \\
310,314,332,335,347,351,357\end{array}$ \\
\hline & $\begin{array}{l}\text { Counselor concern } \\
304,317,323,324,325\end{array}$ \\
\hline & $\begin{array}{l}\text { SI as an ongoing treatment consideration } \\
304,355,357\end{array}$ \\
\hline & $\begin{array}{l}\text { Specific interventions } \\
306,308,310,312,314,315,317,326,329,330,336,337,343,345,346,348,348 \text {, } \\
349,357\end{array}$ \\
\hline & $\begin{array}{l}\text { Unmodified interventions } \\
307,308,310,314,326,332\end{array}$ \\
\hline & $\begin{array}{l}\text { Normalize SI } \\
306,329,330,335,357\end{array}$ \\
\hline & $\begin{array}{l}\text { Client Centered Therapeutic Relationship } \\
310,329,330,335,355\end{array}$ \\
\hline & $\begin{array}{l}\text { Supervision/Consultation/Collaboration } \\
324,330,355\end{array}$ \\
\hline \multirow[t]{3}{*}{ Identification of SI } & $\begin{array}{l}\text { Identification through client self-disclosure } \\
304,317,329,332,336,341,344,345,349,355\end{array}$ \\
\hline & $\begin{array}{l}\text { Identification through observation } \\
306,308,310,312,315,322,329,330,337,341,343,344,345,347,349,355\end{array}$ \\
\hline & $\begin{array}{l}\text { Identification through direct questioning } \\
307,308,310,312,314,317,322,323,325,326,329,330,335,336,337,343,344 \text {, } \\
345,346,347,348,351,357\end{array}$ \\
\hline
\end{tabular}


the greater portion of those I work with who are self-injurious have no suicidal ideation," "there may be a slight increase in relationship to suicide, but that does not seem to be shown in my clients," and "at times, those who self-injure will admit that they have had suicidal ideation in the past."

\section{Functions of Self-Injury}

The category functions of self-injury $(\mathrm{N}=16)$ describes the various motivations or purposes of self-injury, as described by participants. This category focuses on the immediate functions of self-injury and not the underlying causes. Subcategories include self-injury as emotional release, self-injury as emotion regulation, self-injury as a negative coping skill, and self-injury as a coping skill. The subcategory self-injury as emotional release $(\mathrm{N}=6$; frequency $=6)$ was defined by responses that "express the idea that self-injury serves as a form of emotional release or relief" and includes statements such as "self- injury says that you are in emotional pain and are looking for an outlet to rid yourself of it," "they seem to be trying to find a way to release emotions," and "[suicide] is not their ultimate goal. Instead it is to feel some release of pain." Self-injury as emotion regulation $(\mathrm{N}=6$; frequency $=8)$ is similar, but speaks more generally to the emotion regulation function. The definition for this subcategory is "participants express the idea that self-injury is a means of regulating or expressing emotion." Sample codes include "self-injury [is] a method for 'feeling something' as opposed to a state of numbness," "self-injury is often related to self-soothing," and "those who self-injure often do so to feel pain." There existed conflicting opinions in the data regarding the conceptualization of self-injury as an adaptive or maladaptive coping skill. The dichotomous subcategories self-injury as a negative coping skill and self-injury as a 
coping skill reflect this divergence. Responses coded under self-injury as a negative coping skill $(\mathrm{N}=6$; frequency=7) express "the idea that self-injury is a coping skill, but make reference to it as an unhealthy or problematic behavior." Characteristic responses include "self-injury is a maladaptive coping strategy," "I look to replace that negative coping skill with a healthier alternative," and "I believe SI is a problematic coping skill that needs to be addressed as such." Conversely, self-injury as a coping skill $(\mathrm{N}=4$; frequency $=5$ ) is defined as participant responses that "express the idea that self-injury is a means of coping, without specifying it as negative or maladaptive." Participants stated, for instance, "my clients who self-injure do it as a coping technique," "the act of selfinjury is active and often relieves symptoms," and "the self-injury is a temporary relief."

\section{Associated Risk}

The topic of potential dangers emerged in the category associated risk $(\mathrm{N}=31)$. The illustrative subcategories are suicide is not the intention, higher risk, and self-injury does not increase suicide risk. The subcategory suicide is not the intention $(\mathrm{N}=15$; frequency=17) is defined as "participants express the idea self-injury is not intentionally suicidal in nature or equivalent to a suicide attempt." Responses include, for example, "those that self-injure and $[s i c]$ only looking to solve a feeling at that time. They are not thinking to end their life," "those who self-injure may inadvertently kill themselves," and "I do not believe that all self-injuring clients are 'practicing' for suicide or even intend to commit suicide." The definition for higher risk $(\mathrm{N}=20$; frequency=34) is "participants express the idea that there exists a higher safety risk with clients who self-injure. This may be related to fatal or unfatal physical harm." Illustrations include "I believe that clients who self-injure are closer to considering and possibly even going through with 
suicide than client $[\mathrm{sic}]$ who do not self-injure. Clients who self-injure are wanting to feel something and at times may be closer to 'being tired of it all'," "clients who self-injure tend to injure 'deeper' each time, needing a little more self-harm to relieve themselves of the depression they are feeling," and "persons who self-injure are more likely to contemplate, attempt, and complete suicide." In contrast, the subcategory self-injury does not increase suicide risk $(\mathrm{N}=9$; frequency $=9)$ is defined as "participants express the idea that self-injury does not necessarily increase risk. Participants may speak to other risk factors as better indicators of the degree of risk." Descriptive codes include "someone who self inures $[$ sic] risks of suicide may not be very different than those who don't selfinjure views and risks of suicide," "they view self-injury as a controlled method of symptom reduction and do not typically want to die, just feel relief," and "in general, I don't believe that those who self-injure are at heightened risk of suicide."

\section{Suicide Risk Assessment}

Participant ideas concerning suicide risk assessment were evenly split, with some participants endorsing both subcategories. Under the category suicide risk assessment ( $\mathrm{N}=28)$, two subcategories emerged-unmodified suicide risk assessment and modified suicide risk assessment. Responses coded into unmodified suicide risk assessment $(\mathrm{N}=16$; frequency=22) included those in which "participants state that they do not assess for suicide risk differently with clients who self-injure than with clients who do not selfinjure." Examples include "I do not assess differently for clients that self-injure and those that do not. Should either group describe their feelings about suicide, I would go through the proper steps of assisting them to receive help," "I assess for risk of all clients the same as I feel that if we assume someone is at higher risk than [sic] we may miss 
someone with high risk by not asking all questiongs [sic] to everyone," and "I do the same risk assessment with all clients when suicide may be a concern." Some of those who endorsed an unmodified assessment $(\mathrm{N}=6$; frequency $=7$ ) stated that they assess for suicide risk with all clients, regardless of presenting concerns. Others stated that, when a suicide risk is present, their assessment procedures do not differ based on the presence of self-injury. In opposition, modified suicide risk assessment $(\mathrm{N}=18$; frequency=27) is defined as "participants state that they assess differently for suicide risk with clients who self-injure than with clients who do not self-injure." Sample codes include "I understand thy $[s i c]$ are different but I would likely conduct a more detailed trauma and suicide assessment," "I usually assess self-injury regularly as well as increase suicide assessment," and "I assess more carefully and also re-assess more often." Among those who endorsed a modified risk assessment, themes included: assessing for comorbid treatment issues such as trauma and substance use, more frequent assessment for suicide risk, and more thorough assessment procedures.

\section{Treatment Planning and Goals}

Treatment planning and goals $(\mathrm{N}=25)$ is comprised of four subcategoriesspecific treatment plan, replacing behaviors, comorbid treatment considerations, and unmodified treatment plan. Codes in specific treatment plan (frequency $=20$ ) include those in which "participants state that their treatment plan with clients who self-injure includes specific inclusion of self-injury." Participant responses, such as "a goal of eliminating self-injury behavior will be put on the treatment plan when self-injury behaviors are present," "I usually set goals that address the reduction of self-injury," and "I develop a specialized behavior plan for clients with self-injury" are representative of 
this subcategory. Replacing behaviors $(\mathrm{N}=13$; frequency $=11)$ is defined as "participants state that they work with the client to replace self-injurious behaviors with either alternatives to self-injury or other coping skills." Examples of this subcategory include "lessening the use of maladaptive coping skills and learning and increasing use of healthier coping skills becomes one of the treatment goals," "[we use] problem solving to replace that behavior with a healthier alternative," and "[part of the treatment plan is]finding alternatives to the destructive behavior." In comorbid treatment considerations $(\mathrm{N}=7$; frequency=11) topics of trauma, depression, and anxiety emerged. This subcategory's definition is "participants talk about comorbid issues that impact treatment and/or may be a focus for treatment." Participant responses include, for example, "more emphasis needs to be placed on guilt and shame issues as part of overall treatment goals," "treatment goals with clients who self-injure tend to be associated with anxiety/depression management," and "I would generally focus on processing trauma and coping." Unmodified treatment plan $(\mathrm{N}=2$; frequency=2) was only endorsed twice, but was considered significant for inclusion in the analysis. It is defined by "participants state that their treatment of clients who self-injure does not differ markedly from their treatment of other similar clinical issues." One participant stated that self-injury does not necessarily alter treatment planning; however, another participant stated "with depression or anxiety/panic attacks some of the goal would be the same reduction and building of positive coping."

\section{Intervention}

The category intervention $(\mathrm{N}=28)$ was the largest category, containing the most subcategories and frequency counts, and consists of the following subcategories: specific 
interventions, client directed treatment, client-centered therapeutic relationship, supervision/consultation/collaboration, normalize self-injury, unmodified interventions, counselor concern, and self-injury as an ongoing treatment consideration. Responses coded into the subcategory specific intervention $(\mathrm{N}=19$; frequency=37) are characterized by participant statements that "talk about specific interventions they use, which are tailored to the client who self-injures." Illustrative examples include "[I] focus on helping develop skills to enhance communication skills and regulate emotions and tolerate distress...collaborate with client, family, and others," "I include self-care tips and first aid knowledge with them," "one specific focus is always on the emotional state while selfinjuring and what causes these experiences," and "I tend to be goal directed, consistent, and adhere to boundaries that are clear and direct." Interventions addressed in this subcategory include, for example, psychoeducation surrounding the medical risks and possibility of accidental suicide $(\mathrm{N}=7$; frequency $=8)$, identifying the underlying therapeutic issue $(\mathrm{N}=2$; frequency $=2)$, developing other coping skills $(\mathrm{N}=3$; frequency=3), identifying the function(s) of self-injury $(\mathrm{N}=3$; frequency $=3$ ), identifying the triggers for self-injury $(\mathrm{N}=4$; frequency $=4)$, and creating safety guidelines for selfinjury $(\mathrm{N}=3$; frequency $=3)$. Codes within the subcategory client directed treatment $(\mathrm{N}=7$; frequency=12) are those in which "participants state that they do not impose their expectations or goals related to self-injury onto the client." Sample codes include "I want to meet the client where he/she is so treatment goals related to self-injury would depend on client's current perception of self-injury and their current desire to curb or stop the behavior," "sometimes, the client is in such a place that controlled self-injury provides an outlet," and "I do not require clients to stop self-inuring or have that as an immediate 
goal." The category client-centered therapeutic relationship $(\mathrm{N}=5$; frequency=11) is defined as "participants talk about specific aspects of or modifications to the therapeutic relationship that make working with this population more effective." Examples codes are "it comes to the fore in most of my work; not because I am alarmed, but because I have come to believe most self-injurious clients lack an appropriate container in which they can explore self-injury," "my preference is to create a trusting environment where they want to share their pain and ways for trying to extinguish it," and "of course, the basic counseling skills involving good rapport and trust-building are vital with the hope that the client will provide honest information about cutting."

Supervision/Consultation/Collaboration $(\mathrm{N}=3$; frequency=7) includes codes in which "participants talk about the importance of clinical supervision, consultation, and/or collaboration with other medical or mental health professionals in their work with clients who self-injure." Participants spoke about utilizing a collaborative approach, as illustrated in the following quotes: "I have always assisted each who self-injure in receiving a complete psychiatric evaluation with a qualified psychiatrist (and psychologist) in order to co-assist in the best overall treatment for the client," "[I] refer client to appropriate medical care," and "medical doctors need to be involved in the client's overall treatment to monitor any potential irreversible damage or infection as a result of the self-injurious behavior." The definition for normalize self-injury ( $\mathrm{N}=5$; frequency=5) is "participants express the idea that self-injury needs to be normalized in the therapeutic relationship, making it less shameful, taboo, or secret." Codes in this category, such as "I try to engage them in open non-shaming ways" and "[I] reassure [them] that it is more common than what might be believed," speak to the ways in which 
participants attempt to make self-injury less taboo. The definition for unmodified interventions $(\mathrm{N}=6$; frequency $=5)$ is "participants state that their work with clients who self-injure does not differ from their work with clients for whom self-injury is not a known concern." Sample codes for this subcategory include "I approach self-injury as I do other maladaptive behaviors. As long as the client is not actively seeking to end his/her life, then it won't necessarily change the way I would work with the client," "I would consider this component of the client's presenting issues as all others and integrate it into my approach, and "I look to replace that negative coping skill with a healthier alternative, just like I would for any other negative coping skill.” The subcategory counselor concern $(\mathrm{N}=5$; frequency=5) is defined as "participants express concern for the client's safety and/or concern for self in regards to professional liability." Participants made statements such as "I tend to have a greater concern for the client" and "[self-injury impacts my work] due to the increased liability involved." This subcategory speaks to the increased liability and concern for clients who self-injure. However, it should be noted that, when discussing ways in which the presence of self-injury impacts their work, only one participant explicitly mentioned monitoring for suicide risk and no participants said that they directly address suicide in their treatment with clients who self-injure. The final subcategory in the category intervention is self-injury as an ongoing treatment consideration $(\mathrm{N}=3$; frequency=3), which is defined as "participants express the idea that treatment of SI is an ongoing issue that is attended to throughout the therapeutic relationship." Descriptive examples include "[I] continue to discuss the behavior throughout the therapeutic relationship" and "when working with clients who self-injure, 
I tend to monitor the client more in terms of the nature of the injury to ensure the person is not in physical danger."

\section{Identification of Self-Injury}

Three means of identifying self-injury emerged in the category identification of self-injury $(\mathrm{N}=30)$-identification through client self-disclosure, identification through direct questioning, and identification through observation, in ascending order. Identification through client self-disclosure $(\mathrm{N}=10$; frequency $=9)$ is defined as "participants state that they identify self-injury through direct client self-disclosure." Participants noted that "sometimes this comes up when talking about suicidal ideation at intake. At other times, it comes up when asking about daily activities or how they react when days are not going as planned," while others stated that "it is part of pre-assessment intake, during intake." Responses coded into identification through observation $(\mathrm{N}=16$; frequency=19) are those in which "participants state that they identify self-injury through observation of the client and his/her behavior." Examples include "the first thing I do is look for obvious outward signs (i.e., cut marks, burn marks, etc.)" and "I also observe whether the client wears clothing that covers himself or herself up during all seasons. In addition, if I see scars, I will ask about it or other physical signs of self-harm." The third category, identification through direct questioning $(\mathrm{N}=23$; frequency $=23)$, is defined as "participants state that they identify self-injury through directly asking the client." Participants stated, for example, "I ask them" and "I have received very positive responses by asking, "A lot of people who feel the way that you do become involved in self-injurous [sic] behaviors. Are you different from those people or - like them - do you engage in any type of self-injurous [sic] behavior?" 


\section{Discussion}

The results of this study address seven main issues: 1) the relationship between suicide and self-injury, 2) the functions of self-injury, 3) the debate regarding the potential for elevated risk, 4) the issue of whether or not suicide risk assessment should be conducted differently with clients who self-injure, 5) the ways in which self-injury may impact treatment planning and goals, 6) how professional counselors intervene in their work with clients who self-injure, and 7) the means by which identification of selfinjury is made. In many ways, these results mirror the existing literature (i.e. Kakhnovets et al., 2010; Klonsky \& Muehlenkamp, 2007; Miller, Muehlenkamp, \& Jacobson, 2011; Nock et al., 2010; Rudd et al., 2006; Toprak et al., 2011; Turner et al., 2012; Wester \& Trepal, 2005; Whisenhunt et al., 2012).

The lack of consensus regarding the relationship between self-injury and suicide reflects the continued professional debate surrounding this topic (e.g. Claes et al., 2010; Greydanus \& Apple, 2011; Hawton \& Harris, 2008; Maddock et al., 2010; McAuliffe, Arensman, Keeley, Corcoran, \& Fitzgerald, 2007; Muehlenkamp \& Gutierrez, 2004; 2007; Plener et al., 2009; Wichstrom, 2009). Although the increased risk of suicide among people who self-injure has been established (Toprak et al., 2011), the exact nature of this complex relationship has yet to be determined. Some participants in this study talked about the absence of relationship (subcategory self-injury and suicide are unrelated) or the different functions self-injury and suicide serve (category functions of self-injury). Others talked about a greater likelihood of people who self-injure to contemplate suicide or experience similar affective states (subcategory self-injury and suicide are related). A few noted the potential for suicide but stated that they have not 
found suicide to be a factor in their work with clients who self-injure (subcategory relationship is unclear). The research team had hoped this study would serve to clarify the relationship between self-injury and suicide. However, since the data reflect the opinions and experience of practicing professional counselors, this lack of consistency in the data likely points to a complicated and multifaceted relationship which may differ for each client.

The finding that self-injury serves a variety of purposes is supported by the literature. Consistent with Kakhnovets et al., (2010) and Nock et al., (2010), the participants in this study noted the coping function of self-injury-whether they referred to it as maladaptive or neutrally. Participants also discussed self-injury as a means of emotional release (subcategory self-injury as emotional release) and emotion regulation (subcategory self-injury as emotion regulation), which reinforces some of those (e.g., emotion regulation, feeling generation, and self-punishment) described by Turner et al., (2012) and Klonsky and Muehlenkamp (2007). However, no participants made direct statements about self-injury as a means of communicating with others or influencing others. It is uncertain whether the participants failed to mention these functions of selfinjury or if their clinical experience leads them to deny endorsing them. This finding may suggest a movement away from conceptualizing self-injury as manipulative in nature (i.e. influencing others), which is in contrast to the historical tendency to equate self-injury with borderline personality disorder (see Klonsky, 2007).

The category associated risk was the second largest following the category interventions. The subcategory higher risk speaks to participants' perceived increase risk of suicide, severe self-injury, or accidental death among clients who self-injure. This 
elevated risk is supported by the literature. Kakhnovets et al., (2010) identified rates of $31.8 \%$ for suicidal ideation among those who reported one episode of self-injury, compared to nearly $60 \%$ for those who self-injured more than once, and $8.5 \%$ among those with no history of self-injury. However, although suicidal ideation is a known risk factor for suicide (Rudd et al., 2006), not all people who experience suicidal ideation will attempt or complete suicide. Awareness of this concept emerged in the subcategory suicide is not the intention, wherein participants spoke explicitly about the non-suicidal functions of self-injury even when the results are fatal. In the subcategory self-injury does not increase suicide risk, some participants took an antithetical stance to higher risk by stating that the presence of self-injury does not increase risk of suicide. Although this stance is not explicitly supported by the literature, Nock et al., (2010), who found that self-injury is rarely accompanied by suicidal thoughts, support the possible accuracy of this perspective.

The topic of suicide risk assessment was addressed in the present study. Participant responses were split almost equally, with about half endorsing unmodified suicide risk assessment and about half endorsing modified suicide risk assessment. There were occasions on which codes for both unmodified and modified were identified within a singular participant response, suggesting that participants may adjust their assessment procedures on a case-by-case basis. The practices of assessing for comorbid treatment issues such as trauma and substance use, more frequent assessment for suicide risk, and more thorough assessment procedures emerged within the subcategory modified suicide risk assessment. These are affirmed in the literature. An established connection between self-injury and trauma (Kakhnovets et al., 2010) suggests the importance of a thorough 
assessment of potential comorbid treatment issues. Additionally, Janis and Nock (2008) suggested counselors use multiple means of assessing risk of suicide, including open discussions with their clients. Miller, Muehlenkamp, and Jacobson (2011) also discussed the importance of assessing self-injury. The authors note that client self-report may lead to more open and honest discussion of the self-injury, whereas the use of a clinical interview may better assist in accurate classification of the self-injury. Again, this points to the need to employ a variety of assessment methods and procedures when working with clients who self-injure.

Similar to the topic of risk assessment, how self-injury may or may not impact treatment planning was addressed in the present study. A small number of codes were identified for the category unmodified treatment plan, whereas the majority of the participants identified specific treatment plan, indicating that many of the participants in this study explicitly consider self-injury as part of their overall treatment of the client. The topics of behavior replacement (subcategory replacing behaviors) and addressing comorbid treatment considerations (subcategory comorbid treatment considerations) also emerged. The use of alternatives to self-injury is documented and may be advantageous to the client, especially during the process of working through difficult emotions in counseling (Wester \& Trepal, 2005). Also, in consideration of the link between selfinjury and trauma and the overlapping risk factors of substance misuse, low self-esteem, and disordered eating (Kakhnovets et al., 2010), this study supports the importance of addressing comorbidity in treatment planning.

When discussing how the presence of self-injury impacts their clinical work, no participants talked about addressing suicide directly in treatment and only one person 
talked about monitoring for suicide risk. Monitoring severity of wounds was addressed twice in self-injury as an ongoing treatment consideration and psychoeducation on the potential medical complications and risks of self-injury was coded eight times under specific interventions. The limited discussion of suicide and unintentional fatal self-injury within the discussion of implications for treatment may suggest that participants conceptualize self-injury and suicide differently.

Participants in this study spoke about the specific interventions they use in their work with clients who self-injure (subcategory specific intervention). They discussed several ideas: exploring the motivation for self-injury, triggers, collaboration with the client's loved ones, psychoeducation on first aid, setting professional boundaries, and developing coping skills. The concept of not imposing the counselor's values or expectations onto the client emerged in client directed treatment. Participants spoke about the importance of recognizing self-injury as a coping skill for the client and not asking the client to abandon that coping skill in the absence of others means of coping. This practice is supported by Wester and Trepal (2005), who discussed the importance of helping clients develop less lethal alternatives within the process of learning adaptive, non-self-injurious means of coping. Similarly, the importance of a client-centered therapeutic relationship (subcategory client centered therapeutic relationship) was cited several times and reinforces the findings of a study conducted by Whisenhunt et al., (2012), in which professional counselors spoke about the central importance of providing a warm and neutral therapeutic relationship when working with clients who self-injure.

The code counselor concern, in regards to the client's safety and professional liability, was coded only five times in the present study. Considering the high frequency 
of codes under higher risk, this finding was unexpected. A possible explanation may be related to the inclusion criteria for this study. Only participants who scored within the levels 3 and $3 \mathrm{i}$ on the SLQ-R were included in the data analysis. It may be that advanced professional counselors approach their work with clients who self-injure with levels of confidence and self-efficacy similar to those they experience in their work with other clients.

Another finding that was unanticipated by the authors was the frequency with which the subcategory supervision/consultation/collaboration was coded. Given the established elevation of suicide attempts among clients who self-injure (Toprak et al., 2011) and the high frequency of codes regarding higher risk and modified risk assessment, the authors expected to find a greater emphasis on the importance of supervision, peer consultation, and collaboration with other mental and medical health providers. Again, this finding may be partially explained by the inclusion of only advanced professional counselors in the analysis. Advanced professional counselors tend to seek out less supervision and peer consultation and have higher degrees of confidence (McNeill et al., 1992). Likewise, it may be that those professional counselors who chose to participate in this study have extensive experience working with clients who self-injure and, as such, experience a greater efficacy in their ability to manage the multiple dimensions of self-injury. The lack of emphasis on supervision, consultation and collaboration, particularly with medical health professionals, remains unexplained.

An area of analysis in this study that has been largely overlooked in the literature addresses means of identifying self-injury. Participants in this study discussed three means by which they identify whether a client self-injures_-direct questioning, 
observation, and client self-disclosure (category identification of self-injury). This finding raises the question about whether or not client response to direct questioning is an accurate and reliable means of identifying self-injury. Additionally, the use of observation as a means of identifying possible indicators of self-injury is emphasized, but this practice tends to be imprecise and is subject to the counselor's subjective interpretation. The need for a more empirical means of identification is highlighted.

\section{Implications for Practice}

The results of this study highlight some important considerations for professional counselors working with clients who self-injure. Although an aim of this study was to further elucidate the nature of the relationship between suicide and self-injury, the results suggest that professional counselors who work with clients who self-injure hold divergent and sometimes unclear ideas about that relationship. They also appear to differ in their ideas concerning the risk associated with self-injury, with some participants stating that suicide is not the intention and that self-injury does not increase the risk of suicide. Conversely, the potential for higher risk regardless of intent was a prominent topic, with several participants discussing the increased risk of severe self-injury and accidental suicide. Considering the lack of clarity surrounding the relationship between self-injury and suicide, and the recurring discussion of higher risk in this study, we recommend that professional counselors conduct a thorough suicide risk assessment with each client who presents with self-injury. We are cautious to avoid endorsing the idea, though, that clients who self-injure are suicidal. Rather, our intent is to recognize the established risk among this client population and provide appropriate intervention. Similarly, although psychoeducation surrounding the potential risks of self-injury was infrequently 
mentioned by participants, we believe that the repeated discussion of the risk of unintentional fatal self-injury implies a need for direct conversation with clients on this topic. In contrast, and in consideration of the potentially life preserving and adaptive functions of self-injury discussed by participants in this study (i.e. self-injury as emotional release, self-injury as emotion regulation, self-injury as a coping skill), we suggest that professional counselors talk with their clients about what self-injury means to them, the purpose(s) it serves, and the feelings that underlie it. Likewise, a thorough assessment for potential comorbid treatment considerations should be made, as suggested by Hoffman and Kress (2010).

The importance of a strong, client-centered therapeutic alliance is highlighted in this study. Participants talked about approaching clients who self-injure with warmth and neutrality, as well as creating a safe place in which clients can express themselves openly. Professional counselors working with this client population may need to make special efforts to establish a climate of non-judgment, authenticity, and empathy. This can be particularly important to clients who self-injure, as these clients tend to have histories of feeling rejected and stigmatized because of their self-injury (Klonsky et al., 2011). Similarly, based on participant responses within the category client directed treatment, we suggest that professional counselors consider the risks and benefits of asking clients to cease self-injury. For some clients, self-injury may be their only means of coping. To take away self-injury prior to developing other coping skills could potentially be dangerous. However, for those clients who continue to self-injure, parameters should be set around the self-injury and/or the use of replacement behaviors might be indicated. 
Additionally, even though they were not major subcategories of the present study, the topics of counselor concern and collaboration have important applications to clinical work. Professional counselors working with clients who self-injure are encouraged to pay attention to their personal reactions to self-injury and the impact their personal ideas and values may have on the therapeutic relationship. Also, as there is an elevated risk associated with this work (Hoffman \& Kress, 2010), we suggest that professional counselors remain attuned to ways in which their own anxiety may interfere with or alter the therapeutic experience. The importance of professional consultation, supervision, and consultation are highlighted.

The abundance of interventions discussed by participants implies a need of specific treatment approaches tailored to clients who self-injure. As such, we recommend that professional counselors working with clients who self-injure immerse themselves in the available literature and become versed in the treatment interventions most supported for use with this client population (see Klonsky et al., 2011; Muehlenkamp, 2006). Finally, we also suggest that professional counselors use multiple ways of identifying self-injury in their clients; not all clients will self-disclose and many may attempt to hide their self-injury. This reinforces Kakhnovets et al., 2010, who advise that, when counselors identify potential risk factors, they actively screen for the presence of selfinjury.

\section{Implications for Counselor Training}

Consistent with the aforementioned implications for practice, we suggest that counselor educators emphasize the following in their work with counselors-in-training (CITs). There is an uncertainty surrounding the relationship between suicide and self- 
injury. As such, counselor educators should train CITs to assess for suicide risk with all clients who self-injure. Likewise, CITs should be instructed to conduct a thorough assessment for other psychological diagnoses and treatment issues. We believe it is also important to discuss the multiple non-suicidal functions of self-injury and help CITs develop ways to explore these-identifying the purpose(s) of self-injury for each individual client and what it means to her/him.

A prominent theme in this study's results is the importance of creating a safe, nonjudgmental therapeutic relationship. As such, we suggest that counselor educators work with their CITs to become aware of and monitor their personal ideas and values about self-injury and their reactions to clients who self-injure. This will include helping CITs gauge their anxiety surrounding their work with clients who self-injure and their concern for the client. One means of achieving this goal is through emphasizing the importance of appropriate clinical supervision and collaboration with medical and mental health professionals. Supervision and collaboration may be particularly important when working with clients who continue to self-injure, as CITs may require assistance learning how to monitor the self-injury and create compromises with the client to help maintain her/his safety while self-injuring.

Participants in this study spoke at length about the interventions they use in their clinical work, which are tailored to clients who self-injure, and the ways they modify treatment goals when self-injury is present. Accordingly, we believe it is important to direct CITs to current literature that supports evidence based practices for self-injury (e.g. Klonksy et al., 2011; Muehlenkamp, 2006). Additionally, professional continuing 
education training sessions may assist CITs in learning how to most effectively intervene with this client population.

\section{Limitations and Implications for Further Research}

One possible limitation of this study involves the use of the SLQ-R to identify professional counselors who have advanced skill in working with clients who self-injure. This instrument was designed to identify levels of professional skill development among supervisees (Stoltenberg, McNeill, \& Delworth, 1998). Accordingly, when using the SLQ-R with participants who may or may not currently be under supervision, a complication arises. To minimize the impact of this, the researchers added the direction to consider peer consultation in place of clinical supervision when responding to questions on the SLQ-R.

The use of self-report in psychological research is supported (Haeffel \& Howard, 2010); however, we considered this method a potential limitation because we were unable to verify participant eligibility. Moreover, as the survey was anonymous, the researchers were unable to request participants to expand on or elucidate their responses. Accordingly, some responses were considered too vague for inclusion in the study and were coded as insufficient for coding. For example, when asked about whether the presence of self-injury impacts clinical work, one participant stated "depends on client." Another example is, when asked about differences in suicide risk assessment for those who self-injure versus those who do not, one participant stated "I use this as teaching opportunity." Similarly, the anonymous online format prevented the use of member checking, meaning that the resulting analysis was not subjected to critical review by the participants. Although the survey request was sent via racially diverse state, regional, and 
national professional list serves, the final racial makeup of the sample was limited in its racial diversity. As such, the limited representation of racial and ethnic minorities in this study may be considered a limitation. Finally, the limited sample $(\mathrm{N}=31)$ could be considered a limitation of the study. However, saturation of data was achieved early, at response 26, and additional responses were coded to ensure saturation.

The results of this study point to a few major points for future empirical examination. Additional research is needed to address the complex relationship between self-injury and suicide. The results of this study suggest that professional counselors vary in their stances on whether or not a relationship exists and what that relationship may entail. Clarity in regards to this relationship could significantly impact quality of care. A related issue involves the apparently dichotomous participant opinions on whether or not self-injury should be considered when conducting suicide risk assessments. The development of a suicide threat assessment measure for clients who self-injure could assist in reducing associated risk. Finally, as aforementioned, research should address the development of a reliable and valid means for identifying self-injury. 


\section{References}

American Association of Suicidology. (2007). Suicide in the U.S.A.: Based on current (2007) statistics. Retrieved from the American Association of Suicidology website: http://www.suicidology.org/c/document_library/get_file?folderId=248\&name=D LFE-415.pdf

Andover, M. S., Primack, J. M., Gibb, B. E., \& Pepper, C. M. (2010). An examination of non-suicidal self-injury in men: Do men differ from women in basic NSSI characteristics? Archives of Suicide Research, 14,79-88.

Balden, W., \& Wittman, S. (2008). Using online qualitative research methods to your advantage. Retrieved from http://www.marketingpower.com/ResourceLibrary/Documents/Content\%20Partne r\%20Documents/Maritz\%20Research/Using\%20Online\%20Qualitative\%20Resea rch\%20Metho ds.pdf

Brausch, A. M., \& Gutierrezz, P. M. (2010). Differences in non-suicidal suicide and selfinjury attempts in adolescents. Youth Adolescence, 39, 233-242. doi:10.1007/s10964-009-9482-0

Chapman, A. L., \& Dixon-Gordon, K. L. (2007). Emotional antecedents and consequences of deliberate self-harm and suicide attempts. Suicide and LifeThreatening Behavior 37(5), 543-552.

Claes, L., Muehlenkamp, J., Vandereycken, W., Hamelinck, L., Martens, H., \& Claes, S. (2010). Comparison of non-suicidal self-injurious behavior and suicide attempts 
in patients admitted to a psychiatric crisis unit. Personality and Individual Differences, 48, 83-87.

Elo, S., \& Kyngas, H. (2008). The qualitative content analysis process. Journal of Advanced Nursing 62:1, 107-115. doi: 10.1111/j.1365-2648.2007.04569.x

Francis, Johnston, Robertson, Glidewell, Entwistle, Eccles, \& Grimshaw (2010). What is an adequate sample size? Operationalising data saturation for theory-based interview studies. Psychology \& Health, 25:10, 1229-1245. doi: $10.1080 / 08870440903194015$

Greydanus, D. E., \& Apple, R. W. (2011). The relationship between deliberate self-harm behavior, body dissatisfaction, and suicide in adolescents: current concepts. Journal of Multidisciplinary Healthcare, 4, 183-189.

Gunter, T. D., Philibert, R. P., \& Hollenbeck, N. (2009). Medical and psychiatric problems among men and women in a community corrections residential setting. Behavioral Sciences and the Law, 27, 695-711. doi: 10.1002/bsl.887

Haeffel, G. J., \& Howard, G. S. (2010). Self-report: Psychology's four-letter word. The American Journal of Psychology, 123(2), 181-188.

Hawton, K. \& Harriss, L. (2008). How often does deliberate self-harm occur relative to each suicide? A Study of Variations by Gender and Age. Suicide and Life Threatening Behavior, 38, 6.

Hawton, K., Harriss, L., \& Rodman, K. (2010). How adolescents who cut themselves differ from those who take overdoses. European Journal of Child and Adolescent Psychiatry, 19, 513-523. doi: 10.1007/s00787-009-0065-0 
Hawton, K. \& James, A. (2005). ABC of adolescence: Suicide and deliberate self harm in young people. Clinical Review, 330, 891-894.

Hoffman, R., \& Kress, V. (2010). Adolescent nonsuicidal self-injury: Minimizing client and counselor risk and enhancing client care. Journal of Mental Health Counseling, 32, 342-353.

Howson, M. A., Yates, K. M., \& Hatcher, S. (2008). Re-presentation and suicide rates in emergency department patients who self-harm. Emergency Medicine Australasia 20, 322-327. doi: 10.1111

Hsieh, H., \& Shannon, S. E. (2005). Three Approaches to Qualitative Content Analysis. Qualitative Health Research, 15, 1277-1288. doi: 10.1177/1049732305276687

Janis, I. B., \& Nock, M. K. (2008). Behavioral forecasts do not improve the prediction of future behavior: A prospective study of self-injury. Journal of Clinical Psychology, 64 (10), 1164—1174. doi: 10.1002/jclp.20509

Kakhnovets, R., Young, H. L., Purnell, A., L., Huebner, E., \& Bishop, C. (2010). Selfreported experience of self-injurious behavior in college students. Journal of Mental Health Counseling, 32, 4, 309-323.

Klonsky, E. D. (2007). Non-suicidal self-injury: An introduction. Journal of Clinical Psychology, 63(11), 1039-1043. doi: 10.1002/jclp.20411

Klonsky, D., \& Muehlenkamp, J. (2007). Self-injury: A research review for the practitioner. Journal of Clinical Psychology, 63, 1045-1056. doi:

10.1002/jclp.20412 
Klonsky, E. D., Muehlenkamp, J. J., Lewis, S. P., \& Walsh, B. (2011). Nonsuicidal selfinjury: Advances in psychotherapy evidence-based practice. Cambridge, MA: Hogrefe Publishing.

Lauri, S. \& Kyngäs , H. (2005). Developing Nursing Theories (Finnish: Hoitotieteen Teorian Kehittäminen). Werner So“” derström. Vantaa: Dark Oy.

Lloyd-Richardson, E. E., Perrine, N., Dierker, L., \& Kelley, M. L. (2007). Characteristics and functions of non-suicidal self-injury in a community sample of adolescents. Psychological Medicine, 37, 1183-1192. doi:10.1017/S003329170700027X

Luborsky, L., McLellan, T. A., Woody, G. E., O’Brien, C. P., \& Auerbach, A. (1985). Therapist success and its determinants. Archive of General Psychiatry, 42, 602611.

McAuliffe, C., Arensman, E., Keeley, H. S., Corcoran, P., \& Fitzgerald, A. P. (2007). Motives and suicide intent underlying hospital treated deliberate self-harm and their association with repetition. Suicide and Life-Threatening Behavior 37(4), 397-408.

McIntosh, J. L. (2008). U.S.A. suicide: 2008 official final data. Retrieved from the American Association of Suicidology website: http://www.suicidology.org/c/document_library/get_file?folderId=232\&name=D LFE-382.pdf.

McNeill, B. W., Stoltenberg, C. D., \& Romans, J. S. C. (1992). The Integrated Developmental Model of Supervision: Scale development and validation procedures. Professional Psychology: Research and Practice, 23:6, 504-508.

Miller, A. L., Muehlenkamp, J. J., \& Jacobson, C. M. (2009). Special issues in treating 
adolescent nonsuicidal self-injury. In M. K. Nock (Ed.), Understanding nonsuicidal self-injury: Origins, assessment, and treatment (9-18). Washington, DC: American Psychological Association.

Muehlenkamp, J. J. (2006). Empirically supported treatments and general therapy guidelines for non-suicidal self-injury. Journal of Mental Health Counseling, 28(2), 166-185.

Muehlenkamp, J. J. \& Gutierrezz, P. M. (2004). An investigation of differences between self-injurious behavior and suicide attempts in a sample of adolescents. Suicide and Life-Threatening Behavior, 34, 12-23.

Muehlenkamp, J. J., \& Gutierrezz, P. M. (2007). Risk for suicide attempts among adolescents who engage in non-suicidal self-injury. Archives of Suicide Research, 11, 69-82. doi: 10.1080/13811110600992902

Nock, M. N. (2009). Why do people hurt themselves? New insights into the nature and functions of self-injury. Journal of the Association for Psychological Science, 18, $2,78-83$.

Nock, M. K., \& Favazza, A. (2009). Non-suicidal self-injury: Definition and classification. In M. K. Nock (Ed.), Understanding non-suicidal self-injury: Origins, assessment, and treatment (9-18). Washington, DC: American Psychological Association.

Nock, M. K., Prinstein, M. J., Sterba, S. K. (2010). Revealing the form and function of self-injurious thoughts and behaviors: A real-time ecological assessment study among adolescents and young adults. Psychology of Violence, 1, 36-52. doi: 10.1037/2152-0828.1.S.36 
O'Grady, K. A., \& Richards, P. S. (2010). The role of inspiration in the helping professions. Psychology of Religion and Spirituality, 2:1, 57-66. doi: $10.1037 / \mathrm{a} 0018551$

Plener, P. L., Libal, G., Keller, F., Fegert, J. M., \& Muehlenkamp, J. J. (2009). An international comparison of adolescent non-suicidal self-injury (NSSI) and suicide attempts: Germany and the USA. Psychological Medicine, 39, 1549-1558. doi: $10.1017 / \mathrm{S} 0033291708005114$

Reynolds, A. L. (2011). Understanding the perceptions and experiences of faculty who teach multicultural counseling courses: An exploratory study. Training and Education in Professional Psychology, 5:3, 167-174. doi: 10.1037/a0024613

Rubel, D., \& Atieno Okech, J. E. (2009). The expert group work supervision process: Apperception, actions, and interactions. The Journal for Specialists in Group Work, 34:3, 227-250. doi: 10.1080/01933920903032596

Rudd, M. D., Berman, A. L., Joiner, T. E., Nock, M. K., Silverman, M. M., Mandrusiak, M., Van Orden, K., Witte, T. (2006). Warning signs for suicide: Theory, research, and clinical applications. Suicide and Life-Threatening Behavior 36:3, 255-262.

Saldana, J. (2009). The coding manual for qualitative researchers. Thousand Oaks, CA: Sage.

Schreier, M. (2012). Qualitative Content Analysis in Practice. Los Angeles, CA: Sage.

Stoltenberg, C. D., McNeill, B., \& Delworth, U. (1998). IDM supervision, An integrated developmental model for supervising counselors and therapists. San Francisco: Jossey-Bass. 
Toprak, S., Cetin, I., Guven, T., Can, G., \& Demircan, C. (2011). Self-harm, suicidal ideation and suicide attempts among college students. Psychiatric Research, 187, 140-144.

Turner, B. J., Chapman, A. L., \& Layden, B. M. (2012). Intrapersonal and interpersonal functions of non suicidal self-injury: Associations with emotional and social functioning. Suicide and Life-Threatening Behavior, 42, 1. pp. 36-55.

Walsh, B. W. (2006). Treating self-injury: A practical guide. NY: Guilford Press.

Wester, K. L., \& Trepal, H. C. (2005). Working with clients who self-injure: Providing alternatives. Journal of College Counseling, 8, 180-189.

Weston, Gandell, Beauchamp, McAlpine, Wiseman, \& Beauchamp (2001). Analyzing interview data: The development and evolution of a coding system. Qualitative Sociology, 24, 3, 381-400.

Whisenhunt, J., Chang, C., Flowers, L., Brack, G., O’Hara, C., \& Raines, T. (2012). Working with clients who self-injure: A grounded theory approach. Manuscript under review.

White, V. E., McCormick, L., \& Kelly, B. (2003). Counseling self-injurious clients: Ethical considerations. Counseling and Values, 47(3), 220-229.

Wichstrom, L. (2009). Predictors of non-suicidal self-injury versus attempted suicide: Similar or different? Archives of Suicide Research, 13, 105-122. doi: $10.1080 / 13811110902834992$ 